\title{
Network Design towards Sustainability of Chinese Baijiu Industry from a Supply Chain Perspective
}

\author{
Xianglan Jiang $\mathbb{D}^{\mathbb{D}},{ }^{1,2}$ Jiuping Xu $\mathbb{D}^{\mathrm{D}},{ }^{3}$ Jiarong Luo, ${ }^{4}$ and Fei Zhao ${ }^{5}$ \\ ${ }^{1}$ Management School, Sichuan University of Science \& Engineering, Zigong 643000, China \\ ${ }^{2}$ School of Management and Economics, University of Electronic Science and Technology of China, Chengdu 611731, China \\ ${ }^{3}$ Uncertainty Decision-Making Laboratory, Business School, Sichuan University, Chengdu 610064, China \\ ${ }^{4}$ School of Management and Economics, Southwest University of Science and Technology, Mianyang 621010, China \\ ${ }^{5}$ Beijing Science and Technology Co., Three Fast Online, Beijing 100080, China
}

Correspondence should be addressed to Jiuping Xu; xujiuping@scu.edu.cn

Received 6 August 2018; Revised 25 September 2018; Accepted 9 October 2018; Published 1 November 2018

Academic Editor: Fabio Tramontana

Copyright (c) 2018 Xianglan Jiang et al. This is an open access article distributed under the Creative Commons Attribution License, which permits unrestricted use, distribution, and reproduction in any medium, provided the original work is properly cited.

\begin{abstract}
Sustainable supply chain network design has attracted great attention of academia and industry in recent years. Baijiu is one of the world's oldest distilled alcoholic beverages and plays a significant role in Chinese culture and Chinese people's daily life. As the production and consumption of Baijiu have a significant influence on the economic, environmental, and social performance of supply chain management, sustainable supply chain network design decisions are critical to the long-term success of the industry. In concert with the rapidly growing Chinese economy, there is a growing demand for a sustainable Baijiu industry. Therefore, this paper constructs and optimizes a network decision-support model for a sustainable Baijiu industry network design. To achieve this, the Baijiu supply chain is examined and a model is proposed for a design that encompasses economic (costs), environmental (carbon emissions), and social (local employment and regional per capita GDP) dimensions. R language programming is then applied to solve the model. A case example indicated that S1 was the optimal decision for reducing costs, S2 was the optimal solution for minimizing carbon emissions, and S3 was the best for maximizing the social impact. Considering the situation of the Baijiu industry and the focal enterprise, it was concluded that $\mathrm{S} 1$ would be the best solution for the case company. And the results verified the effectiveness of the framework. This paper develops a systematic and effective approach that decision-makers can use to conduct sustainable network design for Baijiu enterprises.
\end{abstract}

\section{Introduction}

Baijiu (Chinese liquor) is one of the world's oldest distilled alcoholic beverages and plays a significant role in Chinese culture and Chinese people's daily life [1-3]. The Baijiu industry is a traditional unique industry that has played a very important role in the development of the Chinese economy, as it is not only a food product but also important cultural heritage $[4,5]$.

Annual Baijiu production in China has steadily increased in recent years and currently exceeds 100 ten thousand kiloliters [6]. China's Baijiu industry has been gaining momentum with annual output exceeding 1,358 ten thousand kiloliters $(\mathrm{kL})$ in 2016, with a year-on-year growth of 3.23\% [7].
Even though the Baijiu industry makes a significant contribution to China's economy, the Chinese liquor industry is also facing fierce competition from international brands and other alcoholic beverages. The current Baijiu industry structure is unreasonable, with the percentage of large companies and medium-sized and small sized enterprises, respectively, accounting for $2.43 \%, 12.55 \%$, and $85.00 \%$ of the industry in 2011 [8]. While China is the biggest producer and consumer of distilled spirits in the world, with consumption accounting for around one-third of total global consumption, the foreign liquor market share in China has been rapidly growing [9]. The average Chinese consumed 9.43 liters of Baijiu in 2013, which was higher than the maximum alcoholic drink volume per person in USA (8.2 liters per annum) [5]. Baijiu not 
only is an important Chinese commodity but also has a very close connection with social and economic activities [5]. In recent years, however, there has been a high-end solidstate fermentation capacity shortage but a low-end liquidstate fermentation overcapacity and the demand and supply imbalance has been growing each year. In China, the logistics costs associated with the liquor industry account for around $20 \%$ of the total costs. The rapid economic growth in China over the past few decades has increased the focus on the environment and the associated social impacts [10]. Further, as liquor production systems can have global ecological impacts, firms are being required to report on the impact their operations have on the local environment [11]. Therefore, the supply and demand imbalances and the unreasonable product structures have become significant roadblocks to Baijiu industry development. Because of this situation and because of the increasing competition from foreign liquor brands, Baijiu enterprises are seeking a sustainable supply chain network design to ensure future development and survival.

With optimization and sustainability becoming more important in recent years, sustainable supply chain network designs (SCND) have attracted significant research and industry attention [11-15]. Sustainability for industry sectors refers to the need to integrate and manage the economic, social, and environmental dimensions, which requires a global view that emphasizes sustainable economic growth, environmental improvements, and social responsibility [13, $16,17]$. Poor designs have been found to have negative environmental, social, and economic implications [18], of which the 12 August 2015 Tianjin warehouse explosion, which caused massive economic damage, environmental pollution, and social impacts, was a typical example. These days, enterprises must be the major contributors to sustainable development [18]. Therefore, as sustainable supply chain design decisions are now vital to long-term business success, the development of sustainable optimal supply chain designs has significant economic, environmental, and social benefits [19].

The speed and dynamism required for modern supply chains present many sustainable challenges for Baijiu production decisions $[11,20]$. Sustainable actions for the Baijiu industry are being motivated by four major drivers: (1) competitive pressures (alcohol drinks, cost reductions, environmental protection, social welfare, and supply chain innovations) [11]; (2) structural imbalances (enterprise imbalance, shortage of high-end solid state fermentation capacity and low-end liquid state fermentation overcapacity, seasonal production, and seasonal consumption); (3) cultural changes (healthy drinking and an aging population); and (4) regulatory pressures (led by corporations, customers, nongovernment organizations, the media, and governments, such as alcohol bans) [11, 20]. Firms are responding to these pressures by demanding more sustainable actions than ever before from their supply chains. However, as past research has tended to focus on the product, with few studies considering supply chain management, there have been few practical and all-encompassing suggestions for sustainable Baijiu network designs. Therefore, a global view of Baijiu's development is needed, which emphasizes sustainable economic growth and relationships between environmental improvements and social equity [17]. Therefore, to reconfigure the Baijiu supply chain, there are several research challenges:

(i) Previous research has only dealt with one or two aspects of sustainability, and few have included all three dimensions in the supply chain [21-24]. To the best of our knowledge, only Xu et al. have proposed a model for a multiobjective SCND problem in a liquor company from an economic perspective [25]

(ii) As measure indices for carbon emissions and the associated social impacts are insufficient for the sustainable supply chain, there is an urgent need to construct a model that can achieve a triple-bottom-line (economic, environmental, and social dimensions) sustainable supply chain network design for the Baijiu industry $[21,26]$

(iii) Few papers have focused on the Baijiu industry from a supply chain perspective [25], with most having focused on product (Luzhou liquor, Fen liquor, and Moutai liquor) [2, 4, 5, 27], production techniques (Daqu, starter, pit mud, and microbiological methods) $[1-3,6,28]$, production processes (fermentation, distillation, and maturation)[3], or waste techniques (waste water and vinasses) [10]. To fully examine the sustainable development of Baijiu, it is necessary to establish a network design for sustainable supply chain management in the Baijiu industry $[21,25]$

(iv) The most common network design method has been CPLEX in supply chain management $[16,18,29,30]$. However, as this design is unable to process two-stage $0-1$ variables models, $\mathrm{R}$ language could be employed to solve these problems $[31,32]$

Sustainable supply chains are vital for industries that have sustainable goals, as, in the modern world, a company's image is no longer related to only having sustainable activities but is instead associated with strong collaborations between all supply chain stakeholders to ensure sustainability [13]. Therefore, considering the present Chinese Baijiu industry situation, there is a need to develop generic network design models that address practical sustainable supply chain design issues. Therefore, the major novelties of this paper are as follows:

(i) For the first time, this study establishes a sustainable network design for the Baijiu industry from a supply chain management perspective that accounts for the economic benefits, the environmental impacts, and the social responsibility

(ii) A multiobjective network design model is proposed to select the optimal solution for the Baijiu supply chain. This is the first model that considers byproduct issues, uses regional per capita GDP as the social index, applies fuzzy AHP to normalize the social coefficients, considers product quantity to evaluate social welfare, and employs $\mathrm{R}$ language to determine the optimal solution

(iii) The proposed model is applied to a large Baijiu enterprise in Sichuan. The findings from this model 
provide new insights into determining an optimal solution under different scenarios and gives decision support to policy-makers seeking to balance Baijiu supply and demand, adjust the industry structure, and promote regional sustainable economic, environmental, and societal development in China

The remainder of this paper is organized as follows. A comprehensive literature review is given in Section 2 and the current status of the Chinese Baiju industry is outlined in Section 3 . The multiobjective model for a sustainable supply chain management Baijiu network design is developed in Section 4, a case study is given in Section 5 to demonstrate the feasibility of the network design, and conclusions are given in Section 6.

\section{Literature Review}

SCND has become an important supply chain management planing problem [33]. Supply chain design and planning involves all major business and industrial activities, all or any of which could have negative environmental or social impacts if not appropriately managed [34, 35]. Distribution centers optimization is an important and systematic task in supply chain operations [24]. Traditionally, the main objective of the optimization models used in network design has focused on the economic dimensions of the supply chain [11, 21]. For example, Agarwal et al. [36] studied transportation networks that had different carriers operating in an alliance, and Zhong et al. [37] proposed an added incentive to motivate carriers to act in the best interest of an alliance when maximizing profits. However, with the growing awareness of environmental and social issues [38], sustainable SCND are being developed, which include long-term economic benefit, social welfare, and environmental aims [26, 38, 39]. However, most network designs have only dealt with one or two dimensions, with very few addressing all three aspects [21]. Generally, while the environmental dimension has received greater attention than social welfare $[22,23]$, the growing awareness of the importance of balancing the social, environmental, and economic objectives has led to an increased focus on sustainable optimal supply chain design and planning [21]. Therefore, to guarantee long-term sustainability, significant research effort has been devoted to extending current approaches to ensure that all three objectives are considered [26].

Driving the ecological pressure on companies has been consumers and production networks. It has now been widely recognized that the Earth's limited natural resources and assimilation capacity are unsustainable in the face of increased global development [11, 40, 41]. Production mode must be changed to achieve a sustainable economy [42]. One of the most considered environmental objectives has been the minimization of emissions that negatively impact human health and climate $[43,44]$. For example, Jiang and Chen [44] investigated a low carbon supply chain in centralized and decentralized settings, Ji and Luo [45] developed a multiobjective, multisourcing intermodal transportation network model factored in carbon emissions, Guillén-Gosálbez and Grossmann [46] measured environmental performance using Eco-indicator 99, Zhang et al. [47] proposed total cost, GHG emissions, and lead time as key sustainability indicators, Govindan et al. [39] proposed a biobjective model that sought to minimize both costs and environmental impacts, and Chaabane et al. [38] developed a framework for the aluminum industry to evaluate the tradeoffs between economic and environmental objectives (GHG emissions) under various cost and operating strategies. Gao and You [12] addressed the life cycle economic and environmental optimization of a supply chain network that considered both design and operational decisions under uncertainty, and Neto et al. [48] presented a framework for the design and evaluation of sustainable logistic networks, in which the profitability and environmental impact were balanced.

Companies also need to stay abreast of impending regulatory risks and manage any risks to their brand reputation from pollution incidents, labor rights controversies, and the like [11]. Not only can social issues threaten a company's brand image but also they impact the economic viability of the entire supply chain $[13,49]$. Many firms adopt corporate social responsibility for improving their reputation due to public concerns over social issues or other benefits [50]. Inhumane working conditions or contamination of the (local) environment has been frequently mentioned as problems $[21,49]$. For example, Pishvaee et al. [51] addressed the problem of socially responsible supply chain network design under uncertain conditions. As external pressure encourages companies to adopt sustainable SCND strategies, these days, an organization's sustainability initiatives and corporate strategy must be closely interwoven [52]. As customers can also develop negative attitudes towards companies that ignore their environmental or social impact, sustainability reputations are now a key issue for companies [52]. Mota et al. [30] proposed a population density that was appropriate for the assessment of strategy decisions, Varsei et al. [49] applied an AHP method to evaluate social factors, and Varsei and Polyakovskiy [18] proposed that social sustainability issues such as employment or the impact on regional GDP be included. Job creation, therefore, has become an important consideration for the social dimension of supply chain designs [53]. Some authors have measured the social effect based on the total number of jobs created by supply chain activities [29]. Zore et al. [35] pointed out that unemployment was currently one of the most severe societal problems, Mota et al. [16] addressed the economic sustainability objective functions using Net Present Value, the environmental sustainability objectives using the ReCiPe Life Cycle Analysis methodology, and the social sustainability objective using a developed GDP-based metric, and Petridis et al. [54] proposed the triple bottom line methods in biomass industry. The sustainable network design researches that have integrated these three dimensions are listed in Table 1. Decision-makers, therefore, need to integrate conflicting sustainability objectives such as profit maximization, GHG emissions reductions, and negative social effects [55].

The classic economic perspective still dominates supply chain research, followed by research that considers the environmental dimension; however, the social dimension has been underrepresented [56]. Companies that claim high 


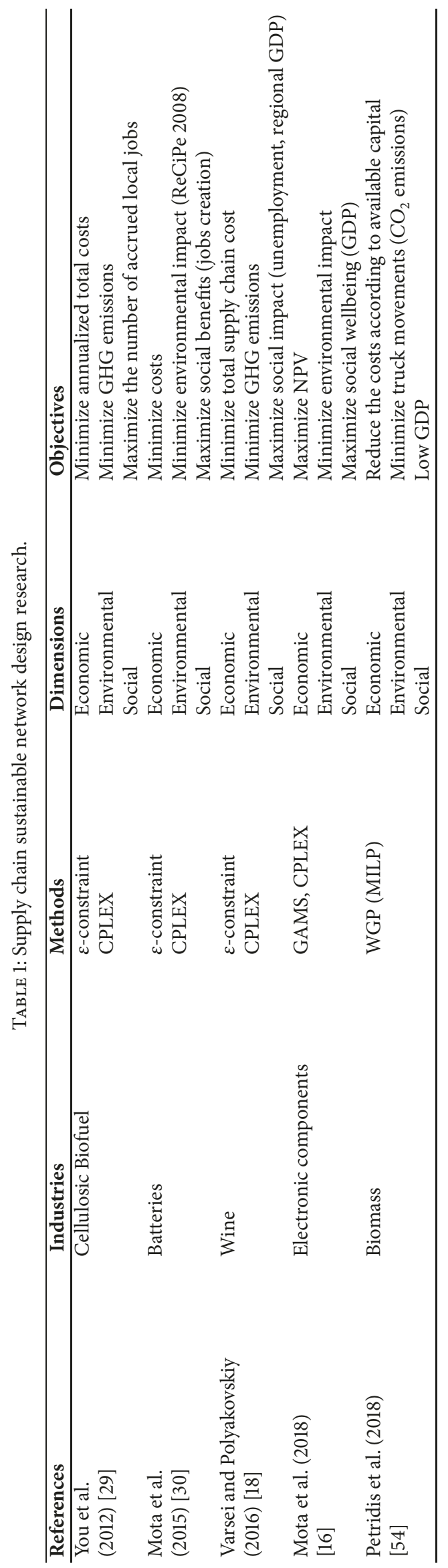


sustainability are more likely to have established processes for stakeholder engagement, are long-term oriented, and disclose a greater amount of nonfinancial information. However, while these sustainable companies significantly outperform their counterparts over the long term in terms of their stock market and accounting performances, sustainability efforts have generally remained focused on incremental eco-efficiencies or cost reductions [11,57]. Despite the Baijiu industry's importance, in the development of the Chinese economy, there has been little research into the Baijiu supply chain. Xu et al. proposed a model for a multiobjective SCND problem for a liquor company [25]. However, despite this effort, to the best of our knowledge, there has been no published research on sustainable Baijiu supply chain network design. Therefore, this paper intends to address this gap by designing a Baijiu supply chain using an optimization approach that considers all three sustainability dimensions.

As alcoholic beverages sustainable supply chain network design studies, Varsei and Polyakovskiy [18] proposed a multiobjective mixed-integer program model to research the wine industry in Australia, which focused on bottling plant location problem. In the general model, the economic objective was minimizing total supply chain cost, the environmental objective was minimizing $\mathrm{CO}_{2}$ emissions, and the social objective was maximizing social welfare (normalized by AHP method through measuring unemployment and regional GDP). The model was solved using the augmented $\varepsilon$-constraint method by CPLEX, and nondominated solutions were obtained. The results indicated that the company's current business model and supply chain structure were not sustainable according to the three defined objectives. This paper is inspired by Varsei and Polyakovskiy's study [18].

\section{Current Status of the Baijiu Industry in China}

China is known as one of the first liquor cultures in the world $[4,58]$. Baijiu is a traditional indigenous distilled spirit prepared from grain fermentation, an ancient technique that can be dated back for 5000 years which uses microorganisms to process and preserve food $[5,7,59]$. Baijiu, which is typically made from cereals, mainly sorghum, through a fermentation, distillation, and maturation process has been regarded as the backbone to fermented product production in China $[5,28]$. Hundreds of different types of Baijiu are produced using various processes in different regions of China, and because of the diverse geographical distributions, climates, manufacturing practices, raw materials, and Daqu, the aroma profiles of the various Chinese Baijiu differ significantly and can be easily distinguished by their manufacturing techniques, fermentation starters, and product flavors with solid state fermentation based on starters (Daqu in Chinese) being the main characteristic [58]. Baijiu can be roughly classified into three categories based on fragrance: sauce fragrance (Maotai-flavor), strong fragrance (Luzhou-flavor), and light fragrance (Fen-flavor) [5].

In recent years, Baijiu has been facing fierce competition. In the alcoholic beverage industry, the Bajiu industry accounted for $60 \%$ of the total industry in 2013, with beer

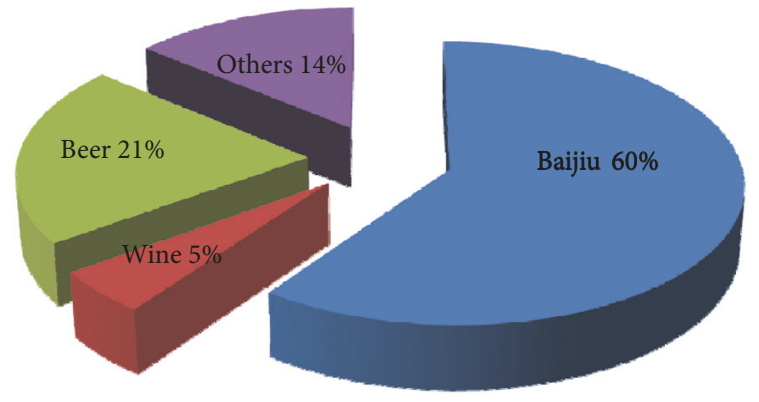

FIGURE 1: Structure of alcoholic beverages in 2013 [60].

sales accounting for $21 \%$, red wine $5 \%$, and others $14 \%$ ( Figure 1) [60]. However, in recent years, younger Chinese have been turning to other foreign liquor brands and other alcoholic beverages.

The Baijiu industry corporate structure is unreasonable. In 2011, there were 1,233 Baijiu enterprises (with turnovers greater than 20 million CNY) in China (National Bureau of Statistics China), 30 large companies, 155 medium-sized companies, and 1,048 small enterprises, which, respectively, accounted for $2.43 \%, 12.57 \%$, and $85.00 \%$ of the market [8]. If all small distilleries such as family workshops were also included, there would be more than 20,000 enterprises.

As the most popular Chinese alcoholic beverage, Baijiu industry has experienced significant changes in past decades [7]. According to the National Bureau of Statistics China, in 2017, total production was approximately 1,198.10 ten thousand kiloliters, a decrease of $-11.80 \%$ from the previous year, with the total sales revenue being 565.40 billion CNY, a $-7.71 \%$ decrease compared to 2016 , and total profit being 102.80 billion CNY, a growth of $28.98 \%$. Production increased from 397.10 ten thousand kiloliters in 2006 to $1,198.10$ ten thousand kiloliters in 2017, with an average annual growth rate of $16.81 \%$, and consumption increased from 383.90 ten thousand kiloliters in 2006 to 1,161.70 ten thousand kiloliters in 2017 , an average annual growth rate of $16.88 \%$. In recent years, due to industrial structural adjustments, there has been a worsening in the supply chain demand imbalance, as shown in Figure 2.

Because of natural resource and historical reasons, liquor production and consumption have certain regional characteristics and large regional disparities. The total national production was 1,198.10 ten thousand kiloliters in 2017, with 372.39 ten thousand kiloliters or $31.08 \%$ being produced in Sichuan Province, the most productive region. The top ten producing provinces in 2017 were Sichuan, Henan, Shandong, Jiangsu, Jilin, Hubei, Heilongjiang, Guizhou, Anhui, and Beijing, as shown in Figure 3.

Baijiu industry logistics costs accounted for about $20 \%$ of total costs in China. As economic growth in China has resulted in serious environmental and social problems, the environmental and social issues associated with liquor production have come under closer scrutiny [11]. The Baijiu production process generates a nondistilled remainder called 

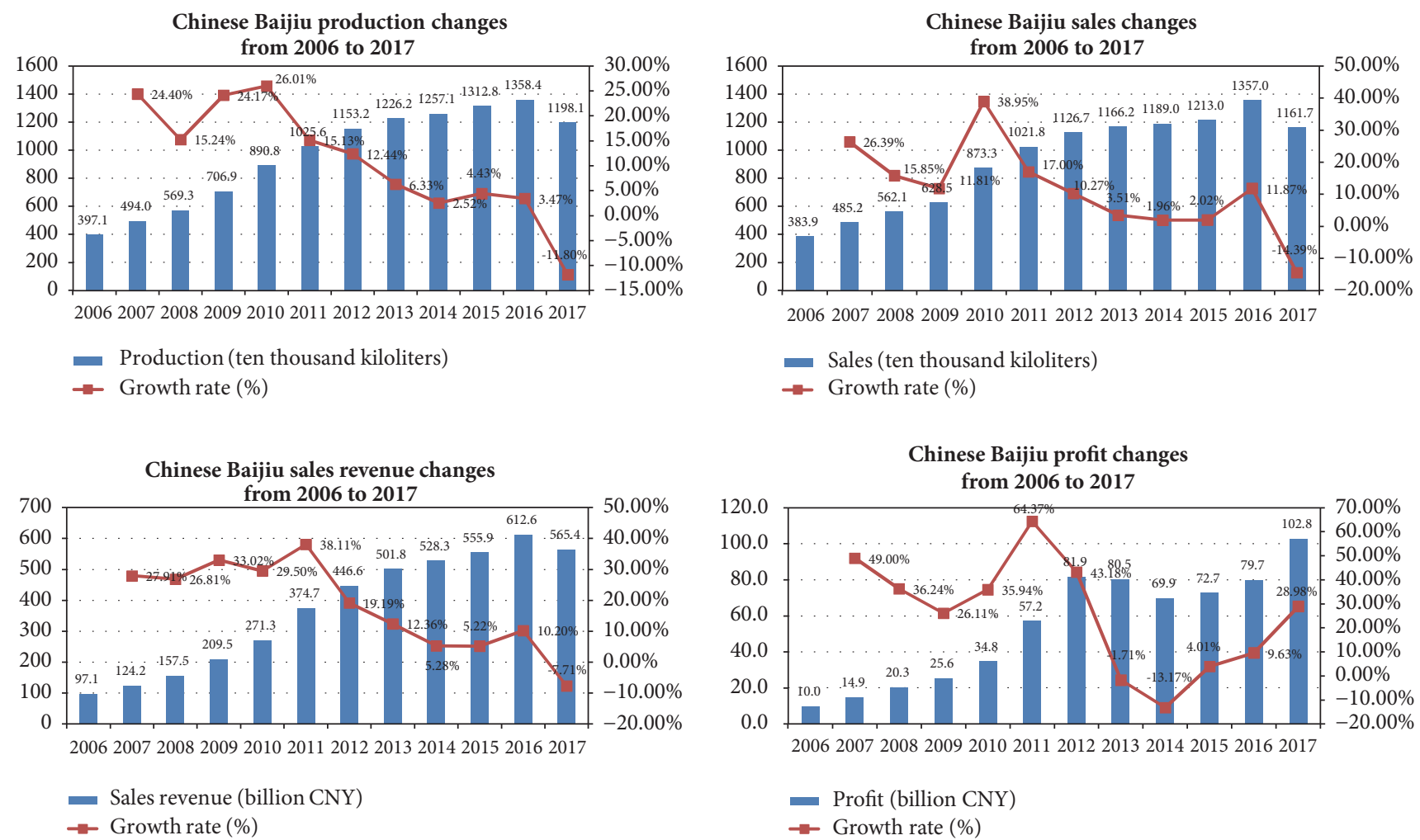

Figure 2: Changes in Chinese Baijiu from 2006 to 2017.

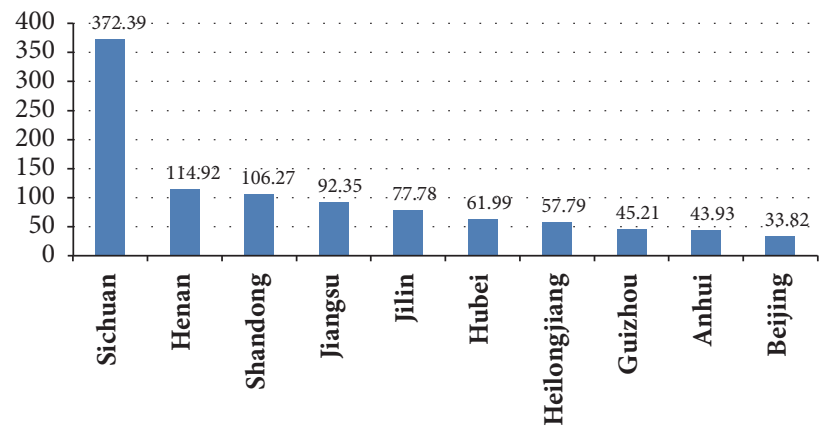

- Production (ten thousand kiloliters)

FIGURE 3: Baijiu production top ten list in 2017.

vinasse, which is low-cost biological resource [10]. However, because of pollution problems, vinasse treatment has become a significant and challenging production process issue for distilled spirit companies. In the past, vinasse was discarded because it rapidly degraded and could not be stored, which resulted in considerable environmental impact [15]. However, a sustainable alternative is to recycle vinasse as cattle feed, fertilizers, or biogas production [10].

\section{Model Formulation}

This section establishes a Baijiu supply chain network design model that considers multiple objectives. The model aims to provide a comprehensive decision support system for the design of Baijiu supply chains which integrates economic benefit, environmental protection, and social considerations. The Baijiu supply chain (Figure 4) has four major stages: suppliers (e.g., cereals and packaging materials), distilleries, distribution centers, and customers (such as exclusive shops, supermarkets, and catering businesses).

In Baijiu industry, through literature review, industry research, and expert opinion, we proposed a model by choosing the critical factors which cover the three dimensions. Therefore, inspired by Varsei and Polyakovskiy [18], the model was formulated as follows. The problem set for the proposed model $S$ represents the supplier set, $s \in S, D$ represents the distilleries set, $d \in D, C$ represents the distribution sets, $c \in C, P$ represents the demand point set, $p \in P, T$ represents the transport mode set, $t \in T$, and $Q$ defines the complete supply chain $q \in Q$ [18].

\section{Parameters}

$c_{\lambda}^{d}$ : Annual fixed costs of buildings and equipment $\lambda$ in distillery $\mathrm{D}$

$c_{i}$ : The $i$ th annual fixed costs of the buildings and equipment in distribution center $\mathrm{C}$

$c_{d}^{m}$ : Unit cost of materials from supplier $\mathrm{S}$ to distillery $\mathrm{D}$

$y_{d}^{m}$ : Quantity of material shipped from supplier S to distillery D

$c_{d}^{p}$ : Per unit production cost at distillery D 


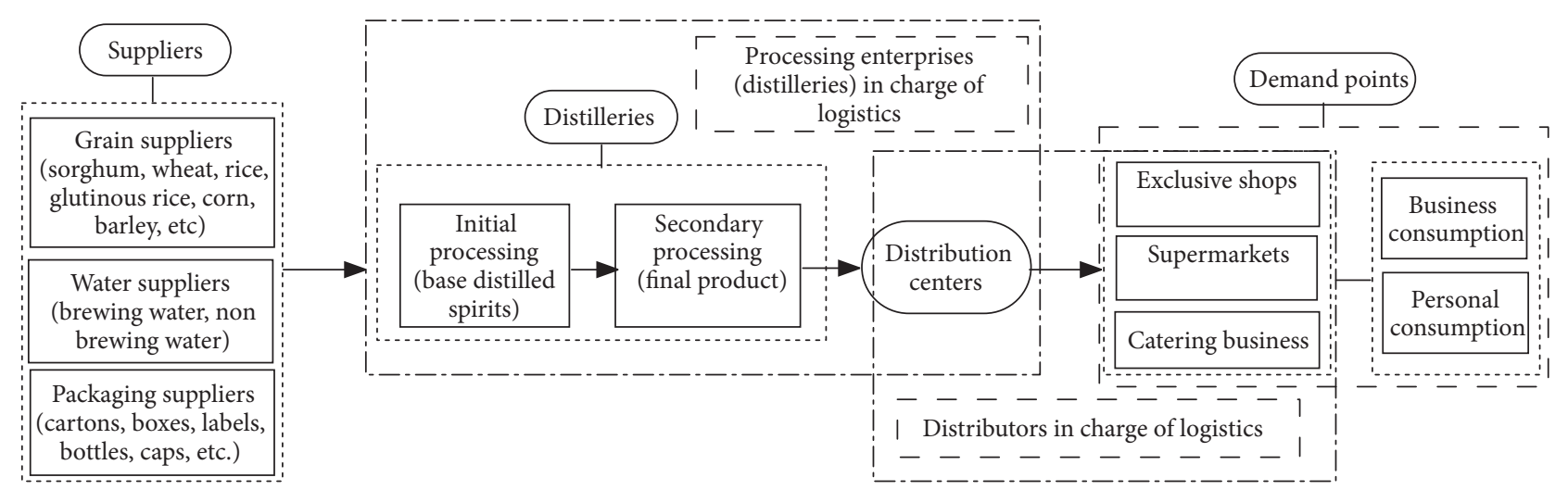

Figure 4: Baijiu supply chain.

$y_{d}^{p}$ : Quantity of product produced by distillery D

$c_{\theta t}^{s d}$ : Unit transportation costs from $\mathrm{S}$ to $\mathrm{D}$ by transportation mode $\mathrm{T}$

$y_{\theta t}^{s d}$ : Quantity of Baijiu transported from S to D by transportation mode $\mathrm{T}$

$c_{\theta t}^{d c}$ : Unit transportation costs from $\mathrm{D}$ to $\mathrm{C}$

$y_{\theta t}^{d c}$ : Quantity of Baijiu transported from D to C

$c_{\theta t}^{c p}$ : Unit transportation costs from $\mathrm{C}$ to $\mathrm{P}$ by mode $\mathrm{T}$

$y_{\theta t}^{c p}$ : Quantity of Baijiu transported from C to P by mode $\mathrm{T}$

$c_{i}^{s}$ : Average storage costs at $\mathrm{C}$

$y_{i}^{s}$ : Quantity of product stored in C

$c_{d}^{w}$ : Average waste disposal costs at D

$y_{d}^{w}$ : Quantity of the waste disposed of at $\mathrm{D}$

$c_{d}^{b}$ : Unit credit for byproduct at D

$y_{d}^{b}$ : Quantity of byproduct at D

$y_{\theta t}^{d c}$ : Quantity of Baijiu transported from D to C by transportation mode $\mathrm{T}$

$c_{\theta t}^{d c}$ : Unit transportation costs from $\mathrm{D}$ to $\mathrm{C}$ by mode $\mathrm{T}$

$e_{p}^{d}$ : Unit emissions $\left(\mathrm{CO}_{2}\right.$ equivalent $)$ produced by distillery D

$e_{\theta t}^{s d}$ : Unit carbon emissions $\left(\mathrm{CO}_{2}\right.$ equivalent) transported from $\mathrm{S}$ to $\mathrm{D}$ by mode $\mathrm{T}$

$e_{\theta t}^{d c}$ : Unit carbon emissions transported from D to C by transportation mode $\mathrm{T}$

$e_{\theta t}^{c p}$ : Unit carbon emissions transported from $\mathrm{C}$ to $\mathrm{P}$ by transportation mode $\mathrm{T}$

$e_{d}^{w}$ : Unit carbon emissions of waste disposed of at distillery D

$j_{q}$ : Job opportunities created across the whole supply chain

$y_{q}$ : Overall production in the supply chain $\phi_{q}$ : Weighting factor for job opportunities across the whole supply chain

$g_{q}$ : Contribution of GDP to the whole supply chain

$\eta_{q}$ : Weighting factor for the contribution of GDP to the whole supply chain

$c_{i}$ : Annual fixed costs for building distribution center $i$ (20 years)

$c_{d}^{f}$ : Annual fixed costs for establishing the distillery (20 years)

$c_{i}^{k}$ : Unit transportation costs from distillery $\mathrm{D}$ to distribution center $i$ by transportation mode $\mathrm{k}$

$c_{i j}$ : Unit highway transportation costs from distribution center $i$ to distribution center $j$ by road

$y_{j}$ : Demand for production at distribution point $j$

$e_{i}^{k}$ : Unit carbon emissions generated by transportation mode $k$ from distillery $\mathrm{D}$ to distribution center $i$

$e_{i j}$ : Unit carbon emission generated by road mode transport from distribution center $i$ to distribution point $j$

$\delta_{d}$ : Average standardized social impact coefficient at distillery D

$\delta_{i}$ : Average standardized social impact coefficient at distribution center $i$

$P_{\lambda}$ : Largest amount of Baijiu in $\lambda$ distillery

$B$ : Maximum annual budget, calculated over 20 years

$\delta_{j}$ : Average standardized social impact coefficient at distribution center $j$

\section{Decision Variables}

$u_{\lambda}^{d}: 1$ if $\lambda$ distillery is established and 0 otherwise

$x_{i}: 1$ if distribution center $i$ is opened and 0 otherwise

$z_{i}^{k}: 1$ if shipped to distribution center $i$ by transportation mode $k$ and 0 otherwise

$z_{i j}: 1$ if road mode is used from distribution center $i$ to distribution point $j$ and 0 otherwise 
4.1. Economic Dimension. The economic goal is to minimize the total supply chain costs $[18,30,39,47]$; that is $T C=$ $T F C+T P C+T M C+T T C+T S C+T W C-T B C$, where TC is the total cost of the supply chain, TFC are the total annual fixed costs of the building and equipment at all facilities in the network, TPC are the total purchase costs of materials supplied by suppliers $S$ to distillery D, TMC is the total manufacturing cost at distillery D, TTC are the total transportation costs, TSC are the total storage costs for Baijiu at the distribution centers, TWC are the total waste disposal costs at the distillery (pot bottom water and waste water from the Baijiu production process), and TBC is the total byproduct credit (vinasse) from the selling of vinasse [15].

$$
\begin{aligned}
T C & =\left(\sum_{\mathrm{d} \in D} c_{\lambda}^{d} u_{\lambda}^{d}+\sum_{c \in C} c_{i} x_{i}\right)+\sum_{d \in D} c_{d}^{p} y_{d}^{p}+\sum_{s \in S} \sum_{d \in D} c_{d}^{m} y_{d}^{m} \\
& +\sum_{t \in T}\left(\sum_{s \in S} \sum_{d \in D} c_{\theta t}^{s d} y_{\theta t}^{s d}+\sum_{d \in D} \sum_{c \in C} c_{\theta t}^{d c} y_{\theta t}^{d c}\right. \\
& \left.+\sum_{c \in C} \sum_{p \in P} c_{\theta t}^{c p} y_{\theta t}^{c p}\right)+\sum_{c \in C} c_{i}^{s} y_{i}^{s}+\sum_{d \in D} c_{d}^{w} y_{d}^{w}-\sum_{d \in D} c_{d}^{b} y_{d}^{b}
\end{aligned}
$$

4.2. Environmental Dimension. The environmental objective is to minimize total annual carbon emissions from the whole Baijiu supply chain operations $[18,47,53]$; that is $T E=T P E+$ $T T E+T W E$, where TPE are the total carbon emissions from the production process, TTE is the transportation stage, and TWE is the waste disposal process. The Baijiu production process consumes water, electricity, and gas, all of which produce a certain quantity of carbon emissions.

$$
\begin{aligned}
T E & =\sum_{d \in D} e_{d}^{p} y_{d}^{p}+\sum_{t \in T}\left(\sum_{s \in S} \sum_{d \in D} e_{\theta t}^{s d} y_{\theta t}^{s d}+\sum_{d \in D} \sum_{c \in C} e_{\theta t}^{d c} y_{\theta t}^{d c}\right. \\
& \left.+\sum_{c \in C} \sum_{p \in P} e_{\theta t}^{c p} y_{\theta t}^{c p}\right)+\sum_{d \in D} e_{d}^{w} y_{d}^{w}
\end{aligned}
$$

4.3. Social Dimension. There are many social impact assessment indices $[16,18,29]$. In this paper, employment and regional per capita GDP are taken as the indices. Unlike previous research, the proposed model assumes that product quantity might impact social welfare.

$$
S W=\sum_{q \in \mathrm{Q}}\left(j_{q} \phi_{q}+g_{q} \eta_{q}\right) \mathrm{y}_{\mathrm{q}}
$$

4.4. Integrated Model. In this model, there are the following assumptions:

(1) Production capacity is able to meet market demand.

(2) Demand in each center is known.

(3) The number of potential plants and distribution centers and their maximum capacities are known.

(4) Customers are supplied with the product from a single distribution center.
As the goal is to provide a solution to the tradeoff between the economic, environmental, and social dimensions, a multiobjective approach is required. Therefore, the general model is $[18,30]$

$$
\begin{array}{ll}
\min & (T C, T E,-S W) \\
\text { s.t. } & y_{d}^{p} \leq P_{\lambda} \\
& \sum_{\mathrm{d} \in D} c_{\lambda}^{d} u_{\lambda}^{d}+\sum_{c \in C} c_{i} x_{i} \leq B \\
& \sum_{c \in C} \sum_{p \in P} y_{\theta t}^{c p} \leq \sum_{d \in D} \sum_{c \in C} y_{\theta t}^{d c} \leq \sum_{d \in D} y_{d}^{p} \\
& \sum_{c \in C} y_{i}^{s} \leq \sum_{c \in C} \sum_{d \in D} y_{\theta t}^{d c} \\
& s \in S \\
& d \in D \\
& c \in C \\
& p \in P \\
& t \in T \\
& q \in Q \\
& u_{\lambda}^{d} \in[0,1], \quad \lambda=1,2, \ldots, h \\
& x_{i} \in[0,1], \quad i=1,2, \ldots, n
\end{array}
$$

The model constraints describe the problem characteristics that need to be guaranteed.

\section{(1) Production Capacity Constraints}

$$
y_{d}^{p} \leq P_{\lambda}
$$

Baijiu production can not exceed the maximum production capacity at each distillery.

\section{(2) Construction Cost Constraints}

$$
\sum_{\mathrm{d} \in D} c_{\lambda}^{d} u_{\lambda}^{d}+\sum_{c \in C} c_{i} x_{i} \leq B
$$

The fixed building cost is budgeted every year for each enterprise and cannot be exceeded.

(3) Product Delivery Quantity Constraint

$$
\sum_{c \in C} \sum_{p \in P} y_{\theta t}^{c p} \leq \sum_{d \in D} \sum_{c \in C} y_{\theta t}^{d c} \leq \sum_{d \in D} y_{d}^{p}
$$

The annual distribution product quantity is smaller than or equal to the production quantity, and the secondary distribution quantity is smaller than or equal to the primary distribution quantity.

(4) Storage Constraints

$$
\sum_{c \in C} y_{i}^{s} \leq \sum_{c \in C} \sum_{d \in D} y_{\theta t}^{d c}
$$




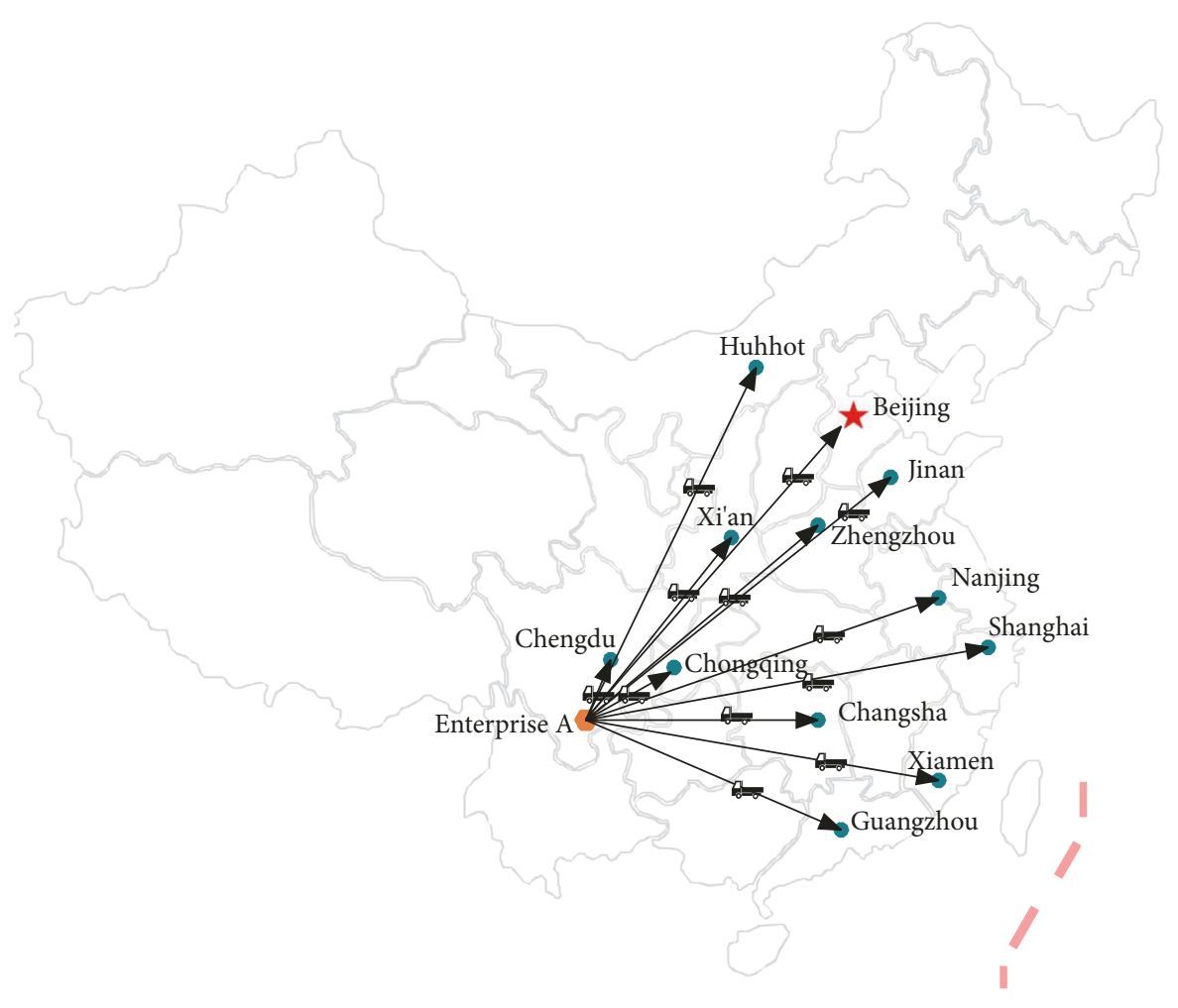

FIgURE 5: Realistic distribution roadmap for Enterprise A, S0.

The distribution center storage capacity is less than or equal to the product quantity delivered to the distribution center.

4.5. $R$ Language. $\mathrm{R}$ is a software environment for statistical computing and graphics and is considered by many to be the premier tool for dealing with prediction problems [31,32]. It is a public domain project similar to the commercial S language and environment developed at Bell Laboratories by John Chambers and colleagues. $\mathrm{R}$ is widely used for big data research, while $S$ is widely used as an educational language and research tool $[31,32]$.

$\mathrm{R}$ is quite similar to other programming packages such as MatLab, as it has an organized layout and several extra options and is more user-friendly than programming languages such as $\mathrm{C}$ or Fortran. RStudio is a user interface for $\mathrm{R}$, so in this paper, both $\mathrm{R}$ and the RStudio interface are used in the application of the Rglpk package [31].

\section{Application Example}

Many factors influence Baijiu production: moisture content, raw material variety, geographical location, temperature control, climate, and water [1]. Therefore, because of its ideal conditions, the southern Sichuan Province has been the main liquor producing region in China [27]. Based on the above model, an example is given in this section for optimizing the supply chain network design of a focal Baijiu company. As Chinese liquor production and sales have strong regional characteristics, in this case example, even though it is a national well-known Baijiu brand, the main sales regions are in the southwestern cities of Chengdu and Chongqing.

5.1. Example Background. To model the case enterprise's supply chain, the large Baijiu enterprise A is in city B, Sichuan Province, which is suitable for Baijiu production. The Baijiu supply chain has its own unique characteristics, as shown in Figure 4. Supplies from the raw materials suppliers to the distilleries are transported by the suppliers, and the distilleries are responsible for the transport to the distributors. The current distribution network is 12 rented warehouses spread across the country in Chengdu, Chongqing, Guangzhou, Changsha, Shanghai, Zhengzhou, Beijing, Xiamen, Jinan, Xi'an, Nanjing, and Hohhot (Figure 5). To meet the required consumer service level, the distillery's current distribution mode is to use trucks and highways to distribute the Baijiu product to the 12 distribution centers. Because the enterprises are facing increasingly fierce competition, rising rents, high logistics cost, high freight vehicle emissions, negative environmental impact, and other matters, to control supply chain costs, reduce the environmental impact, and maximize social influence, the company intends to diversify its distribution modes. On-road vehicle emissions are a major source of transport emissions, and the average road cost is higher than either rail or river transport [18]. The transportation sector accounts for $26 \%$ of global delivered energy consumption and $22 \%$ of global $\mathrm{CO}_{2}$ emissions, $75 \%$ of these from road transportation; therefore, fossil fuel use must be reduced 
TABLE 2: Carbon emissions factor in kilograms per tonne kilometer.

\begin{tabular}{ccc}
\hline Transportation mode & Emission factor & Type \\
\hline Rail & 0.0165 & Average locomotive \\
Road & 0.0556 & Big truck \\
River & 0.0133 & Container ship \\
\hline
\end{tabular}

to ensure supply security and emissions reductions within the transportation sector [61]. Railway and river transport, however, are safe, low cost, and have low carbon emissions. Therefore, the company decides to use road, rail, and waterway transportation. Because of the high cost and rising rents, the company intends to select 3 cities from the 12 cities as the main distribution centers and use highway, railway, or waterway transport from the distillery to these 3 distribution centers, from where trucks deliver directly to the other distribution points in the 9 cities, which would allow for timely customer response. To achieve this goal, the company has decided to internalize its distribution centers. Therefore, the optimization of the current logistics network can be defined as a supply chain strategic decision that considers the logistics costs and the environmental and social impacts as this company is seeking to build an image of sustainability. This assists in the analysis of the gap between the existing network and the optimal network in terms of the economic, environmental, and social goals.

The company is now facing the following issues: (1) which three cities to select as the distribution centers to minimize supply chain costs and the environmental impacts and maximize the social impact; (2) which transportation modes to select to achieve the optimal goals; (3) the uncertain delivery volume at each distribution center; (4) how the three distribution centers can meet the delivery volumes required at the other nine distribution points to minimize costs and the environmental impact and maximize social welfare; (5) what the social impact coefficients are for the distillery, the three distribution centers, and the nine distribution points. All issues need to be resolved using the model algorithm, as the model involves $0-1$ variables for transportation mode selection, distribution center selection, and secondary distribution point path selection.

The carbon emissions shown in Table 2 are calculated based on the emissions factor statistics published by China's transportation department.

In this study, two equally weighted social categories associated with the distribution center locations are considered: unemployment rate $[18,30,35]$ and regional per capita gross domestic product (GDP). From social sustainability perspective, based on previous studies, the company prefers distribution centers where umemployment is higher and regional per capita GDP is lower [18, 30].

To measure the social impact, a fuzzy analytic hierarchy process (fuzzy AHP) and its associated pairwise comparison scale are proposed (Tables 3 and 4). This method is used to score each distribution center location based on the two selected social categories to determine the social coefficient. Fuzzy AHP has been extensively used as a multicriteria
TABLE 3: Unemployment comparison scores.

\begin{tabular}{ccc}
\hline Score (\%) & Linguistic variables & Membership function \\
\hline$[0-0.5)$ & No impact & $(1,1,1)$ \\
{$[0.5-1)$} & Between $\widetilde{1}$ and $\widetilde{3}$ & $(1,2,3)$ \\
{$[1-1.5)$} & Weak impact & $(2,3,4)$ \\
{$[1.5-2)$} & Between $\widetilde{3}$ and $\widetilde{5}$ & $(3,4,5)$ \\
{$[2-2.5)$} & Strong impact & $(4,5,6)$ \\
{$[2.5-3)$} & Between $\widetilde{5}$ and $\widetilde{7}$ & $(5,6,7)$ \\
{$[3-3.5)$} & Very strong impact & $(6,7,8)$ \\
{$[3.5-4)$} & Between $\widetilde{7}$ and $\widetilde{9}$ & $(7,8,9)$ \\
{$[4-4.5)$} & Extreme impact & $(8,9,9)$ \\
\hline
\end{tabular}

TABLE 4: Scores for the rate of regional per capita GDP of national per capita GDP.

\begin{tabular}{lcc}
\hline Score (\%) & Linguistic variables & Membership function \\
\hline$[4-4.5)$ & No impact & $(1,1,1)$ \\
{$[3.5-4)$} & Between $\widetilde{1}$ and $\widetilde{3}$ & $(1,2,3)$ \\
{$[3-3.5)$} & Weak impact & $(2,3,4)$ \\
{$[2.5-3)$} & Between $\widetilde{3}$ and $\widetilde{5}$ & $(3,4,5)$ \\
{$[2-2.5)$} & Strong impact & $(4,5,6)$ \\
{$[1.5-2)$} & Between $\widetilde{5}$ and $\widetilde{7}$ & $(5,6,7)$ \\
{$[1-1.5)$} & Very strong impact & $(6,7,8)$ \\
{$[0.5-1)$} & Between $\widetilde{7}$ and $\widetilde{9}$ & $(7,8,9)$ \\
{$[0-0.5)$} & Extreme impact & $(8,9,9)$ \\
\hline
\end{tabular}

decision-making tool in diverse applications [21]. In this paper, a smaller score means a better social performance.

Table 5 shows the unemployment rate and regional per capita GDP based on statistics published by the National Bureau of Statistics China and China's Local Bureau of Statistics. It also shows scores assigned to the regions based on the comparison scale in Tables 3 and 4 . The scores are based on decision-makers' judgments on the unemployment and the regional per capita GDP rates in these cities. Based on these scores, Table 5 gives the normalized social coefficients for unemployment and per capita GDP. As twelve distribution centers are considered in this study, it is assumed that the lower the normalized social coefficients, the greater the social impact at the distribution center locations.

5.2. Optimal Model. The following takes Enterprise A's supply chain as an example to design the optimal sustainable network. In the model, the selection and optimization of the distribution centers and transportation modes are mainly considered. The economic objective is to minimize supply chain costs: purchasing costs from suppliers to distillery, production costs at the distillery, transportation costs, production waste disposal costs, byproduct credit at the distillery, and the fixed costs associated with the distillery and the distribution centers. 


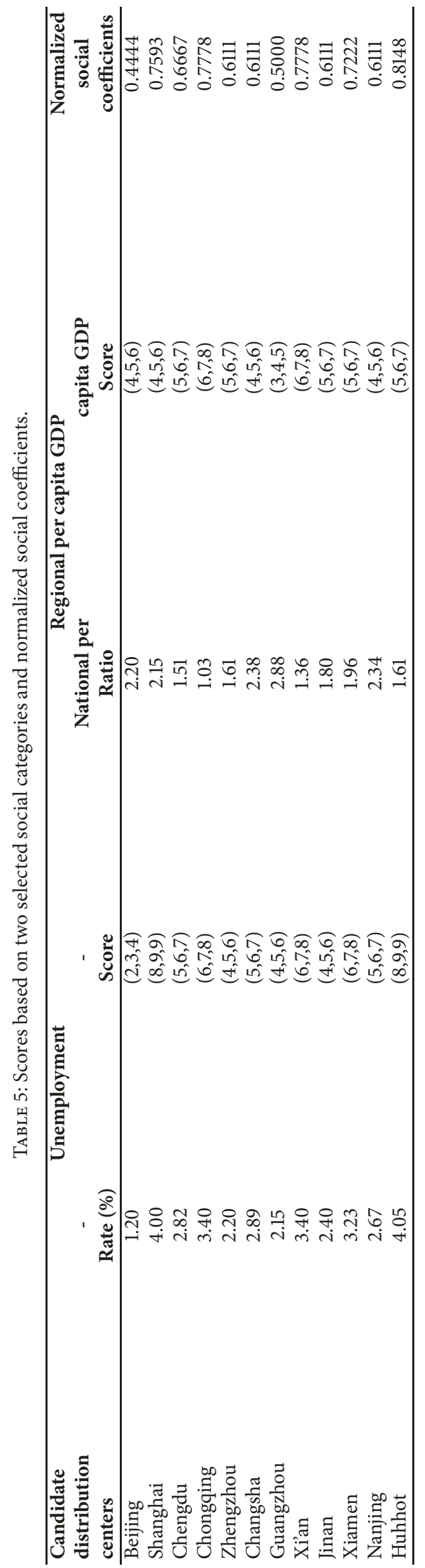




$$
\begin{aligned}
& \mathrm{f}_{1}(x, y)=\left(\sum_{i=1}^{n} c_{i} x_{i}+c_{d}^{f}\right)+c_{d}^{p} y_{d}^{p}+c_{d}^{m} y_{d}^{m} \\
& +\left[\sum_{i=1}^{n} x_{i} \sum_{k=1}^{u} z_{i}^{k} c_{i}^{k}\left(y_{i}+\sum_{j \neq \mathrm{i}}^{m} z_{i j} y_{j}\right)\right. \\
& \left.+\sum_{i=1}^{n} \sum_{j \neq i}^{m} z_{i j} y_{j} c_{i j}\right]+\sum_{i=1}^{n} x_{i} c_{i}^{s}\left(y_{i}+\sum_{j \neq i}^{m} z_{i j} y_{j}\right) \\
& +c_{d}^{w} y_{d}^{w}-c_{d}^{b} y_{d}^{b}
\end{aligned}
$$

The environmental objective minimizes the carbon emissions generated by the production and transportation, which can be expressed with the following function:

$$
\begin{aligned}
\mathrm{f}_{2}(x, y)= & e_{d}^{p} y_{d}^{p}+\sum_{i=1}^{n} x_{i} \sum_{k=1}^{u} z_{i}^{k} e_{i}^{k}\left(y_{i}+\sum_{j \neq \mathrm{i}}^{m} z_{i j} y_{j}\right) \\
& +\sum_{i=1}^{n} \sum_{j \neq i}^{m} z_{i j} y_{j} e_{i j}+e_{d}^{w} y_{d}^{w}
\end{aligned}
$$

The social objective is to maximize the social influence of the distillery and distribution centers. Social influence is closely related to local employment and per capita GDP, which has a direct relationship with production and distribution volumes.

$$
\begin{aligned}
\mathrm{f}_{3}(x, y)= & \delta_{d} y_{d}^{p}+\sum_{i=1}^{n} x_{i} \delta_{i}\left(y_{i}+\sum_{j \neq i}^{m} z_{i j} y_{j}\right) \\
& +\sum_{i=1}^{n} \sum_{j \neq i}^{m} \delta_{j} z_{i j} y_{j}
\end{aligned}
$$

In the sustainable supply chain network optimization for Baijiu enterprises, it is necessary to minimize supply chain costs and the environmental impact and maximize social welfare. Therefore, the overall model is as follows:

$$
\begin{array}{ll}
\min & f(x, y)=\left(f_{1}(x, y), f_{2}(x, y),-f_{3}(x, y)\right) \\
\text { s.t. } & y_{d}^{p} \leq P \\
& \sum_{\lambda=1}^{\mathrm{h}} c_{\lambda}^{d} u_{\lambda}^{d}+\sum_{i=1}^{n} c_{i} x_{i} \leq B \\
& \sum_{i=1}^{n} y_{i}+\sum_{j \neq i}^{m} y_{j} \leq y_{d}^{p} \\
& \sum_{i=1}^{n} x_{i}=3 \\
& \sum_{i=1}^{n} x_{i}+\sum_{j \neq i}^{m} x_{j}=12
\end{array}
$$

$$
\begin{array}{ll}
u_{\lambda}^{d} \in[0,1], & \lambda=1,2, \ldots, h \\
x_{i} \in[0,1], & i=1,2, \ldots, l \\
z_{i}^{k} \in[0,1], & k=1,2, \ldots, u \\
z_{i j} \in[0,1], & j \neq i, j=1,2, \ldots, m
\end{array}
$$

To determine a feasible solution to the case, there are the following constraints.

\section{(1) Construction Cost Constraints}

$$
\sum_{\mathrm{d} \in D} c_{\lambda}^{d} u_{\lambda}^{d}+\sum_{c \in C} c_{i} x_{i} \leq B
$$

There is a set annual budget for building the fixed facilities.

\section{(2) Product Delivery Volume Constraints}

$$
\sum_{i=1}^{n} y_{i}+\sum_{j \neq i}^{m} y_{j} \leq y_{d}^{p}
$$

The delivery volume to all distribution centers and distribution points is less than the products produced.

(3) Choose Only 3 Cities as Distribution Centers from Possible 12 Cities

$$
\sum_{i=1}^{n} x_{i}=3, \quad i=1,2, \ldots n
$$

\section{(4) Meets the Demand in All 12 Cities}

$$
\sum_{i=1}^{n} x_{i}+\sum_{j \neq i}^{m} x_{j}=12, \quad i=1,2, \ldots n, j=1,2, \ldots, m .
$$

5.3. Results and Discussions. Better data decision-support tools and incentives are needed to move from simply managing supply chains to predicting and preventing unsustainable practices [11]. In this section, $\mathrm{R}$ language is used to solve the optimization model for Enterprise A and analyze the current supply chain design and compare it with other possible scenarios. The results are expressed in Table 6. The model is calculated by considering each individual objective function [18].

Scenario So. It is the actual scenario in which Enterprise A produces Baijiu in a single large-sized distillery designated as city B, Sichuan Province. The current distribution network is 12 rented warehouses in Chengdu, Chongqing, Guangzhou, Changsha, Shanghai, Zhengzhou, Beijing, Xiamen, Jinan, Xi'an, Nanjing, and Huhhot with the products being transported by road to meet demand. In addition to distribution, all warehouses are direct sales points to serve local customers. The total costs for the Baijiu company are costs for raw materials purchase, production costs, distribution costs, fixed 
TABLE 6: Current model and the optimal solutions under three dimensions (T1: road; T2: rail; T3: river).

\begin{tabular}{cccccr}
\hline Scenario & $\begin{array}{c}\text { Total cost } \\
\text { (CNY per year) }\end{array}$ & $\begin{array}{c}\text { Carbon emission } \\
\text { (tonnes per year) }\end{array}$ & $\begin{array}{c}\text { Social } \\
\text { impact }\end{array}$ & $\begin{array}{c}\text { Distribution } \\
\text { center }\end{array}$ & $\begin{array}{c}\text { Transportation } \\
\text { mode }\end{array}$ \\
\hline S0 & $3,278,818,369.01$ & $227,493.13$ & $273,951.80$ & 12 (Rental) & T1 \\
S1 & $3,225,352,575.28$ & $223,443.35$ & $346,538.26$ & 3 (Build) & Level 1: T2, T3; Level 2: T1 \\
S2 & $3,229,894,225.58$ & $222,072.11$ & $346,538.26$ & 3 (Build) & Level 1: T2, T3; Level 2: T1 \\
S3 & $3,383,864,098.32$ & $237,121.71$ & $467,487.52$ & 3 (Build) & Level 1: T2, T3; Level 2: T1 \\
\hline
\end{tabular}

investment at the distillery (20 years annual investment), rental fees at the 12 distribution centers, warehousing costs at the 12 distribution centers, waste disposal costs, and the gains from selling the byproduct $[18,30,39,47]$. The distribution roadmap for the existing enterprise is shown in Figure 5.

Scenario S1 (an optimal solution obtained when minimizing cost). Using $\mathrm{R}$ language, three cities are selected as the distribution centers from the existing 12 rental distribution points, with lowest total cost being the goal, from which 220 programs were obtained. The total supply chain cost is the lowest when distribution centers in Chongqing, Changsha, and Zhengzhou are chosen, as shown in Figure 6. Distribution from Enterprise A to Chongqing is by waterway and from Enterprise A to Changsha and Zhengzhou is by rail. Road vehicle distribution is used from the three distribution centers to the other nine distribution points to guarantee customer demand. With this distribution method, the total supply chain cost for Enterprise A is reduced to $3,225,352,575.28 \mathrm{CNY}$, a cost saving of 53,465,793.73 CNY, or $1.63 \%$ compared with S0, with the cost savings being mainly transportation costs. The annual carbon emissions are $223,443.35$ tonnes, a decrease of $4,049.78$ tonnes or $1.78 \%$ compared with S0. The social influence is 346,538.26, an increase of $72,586.46$ or $26.50 \%$ over S0. The changes and variable costs for all 220 programs are described in Figure 7. The scatter diagram of costs is depicted in Figures 8(a) and 8(b).

Scenario S2 (an optimal solution obtained by minimizing the environmental impact). Using $\mathrm{R}$ language to minimize environmental impact, 220 solutions were obtained. The smallest environmental impact plan is selecting Chongqing (waterway), Changsha (railway), and Zhengzhou (railway) as the distribution centers, the network route map for which is showed in Figure 9. The total supply chain cost is $3,229,894,225.58 \mathrm{CNY}$, a saving of $48,924,143.43 \mathrm{CNY}$ or $1.49 \%$ compared to the existing mode. Carbon emissions are $222,072.11$ tonnes, a reduction of $5,421.02$ tonnes or $2.38 \%$ compared with S0. The social influence is $346,538.26$, an increase of $72,586.46$ or $26.50 \%$ compared to S0, which is consistent with the social impact of the cost-optimal scenario in S1. The distribution and carbon emissions scatter diagram are described in Figures 10(a) and 10(b).

Scenario S3 (optimal solution that maximizes the social benefit). Quantifying the social dimension is a key challenge [53]. The best solution for maximizing social influence is to build the distribution centers in Shanghai (waterway), Xiamen (railway), and Nanjing (waterway), the network layout for which is depicted in Figure 11. The total supply chain cost for Enterprise A is 3,383,864,098.32 CNY, an increase of $105,045,729.31 \mathrm{CNY}$ or $3.20 \%$ compared to S0, carbon emissions are 237,121.71 tonnes, 9,628.58 tonnes more than S0, an increase of $4.23 \%$, and social influence is $467,487.52$, an increase of $93,535.72$ or $70.65 \%$ on S0. This program shows a significant increase in the social influence of the supply chain, however, at the same time, the costs and carbon emissions also increase. The distribution map for the 220 social influence schemes is described in Figure 12.

Compared to S0, S1, S2, and S3 are better configurations as they improve all three objectives. Therefore, this analysis shows that the company should implement one of these scenarios and change its business model and distribution center locations. The company gains from the multiple transportation methods (river, rail, and road), the reduced costs, and emissions and the increased social impact advantages from the designed networks compared to the current model. As road transport is the main mode for the transport of a majority of commodities, the road mode was used to meet the customer need in the second tier [18]. A Comparison of the costs of the different scenarios and their distribution modes in Table 6 clearly shows that higher social benefits come with higher costs, which is consistent with previous research [30]. In the minimizing cost scenario (S1), Figure 6 shows that it is possible to achieve cost reductions compared to the current scenario (-1.63\%). When minimizing the environmental impact, the cost savings were $1.49 \%$ compared to the current scenario, and the environmental impact decreased by $2.38 \%$. When maximizing the social benefit, the costs and carbon emissions increased accordingly.

Chinese Baijiu industry is faced with shortage of highend solid state fermentation capacity and overcapacity for low-end liquid state fermentation, and there are imbalances between supply and demand. Baijiu industry faces intense competition both at home and abroad. Therefore, as the focal enterprise is also facing fierce competition for survival and development, they need to pay more attention to the economic aspect. According to the three optimization scenarios (Table 6), the total cost ranking was identified as $S 3>S 0>$ $S 2>S 1$. The cost of $\mathrm{S} 1$ with $13,225,352,575.28 \mathrm{CNY}$ ranked the lowest one. Therefore, the focal enterprise would give priority to S1. In recent years, the Baijiu industry has established an environmental-friendly production system, so the negative impact on the environment was relatively small. As shown in 


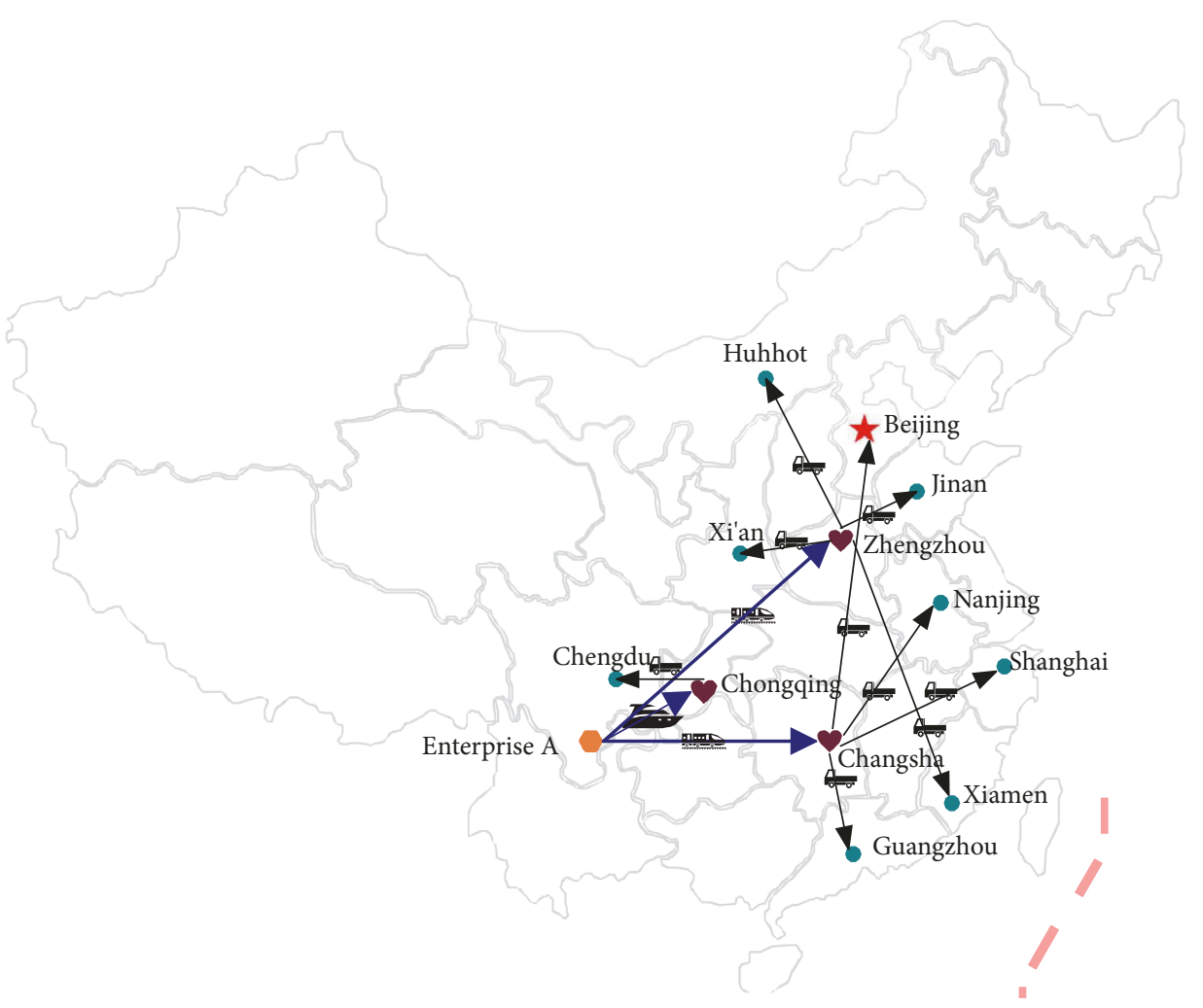

FIGURE 6: Optimal solution by minimizing the costs of Enterprise A, S1.

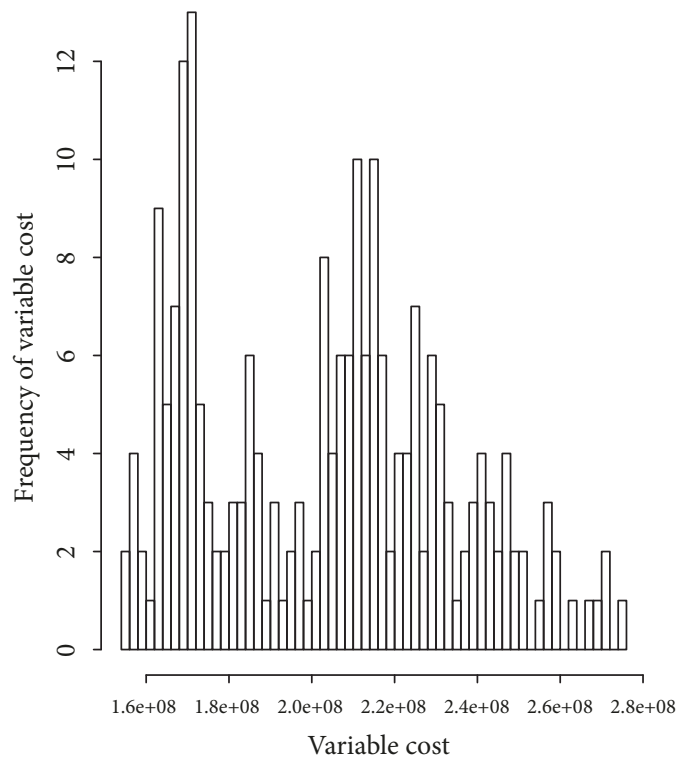

FIGURE 7: Distribution of variable costs, S1.

Table 6, the carbon emissions ranking was $S 3>S 0>S 1>$ $S 2$. And the annual carbon emissions of S1 had a decrease of $4,049.78$ tonnes or $1.78 \%$ compared with S0, which was better than the current scenario S0. Baijiu enterprises are placing greater attention on social responsibility, providing employment opportunities and promoting local economic development. The social impact ranking was obtained as $S 3>$ $S 1=S 2>S 0$, as shown in Table 6. And the social impact of S1 was $346,538.26$, an increase of $72,586.46$ or $26.50 \%$ over S0, which was better than S0. Therefore, considering the situation of the focal enterprise and the Baijiu industry, it was concluded that S1 would be the best solution for the enterprise.

According to the results, the enterprise's current network and business model are not sustainable and efficient. In our case example, we obtained three optimal solutions by $\mathrm{R}$ language. From a comprehensive consideration of the industry, S1 was the best solution in terms of the development of the focal company. The proposal was only a preliminary recommendation, as the final plan would be decided by the Board of Directors. And the model would be tested in actual operations.

5.4. Comparisons. This study was inspired by Varsei and Polyakovskiy's work [18]. However, due to different supply chains and different production processes, techniques, and supply chain operations, there are many differences between the two studies.

(1) Industry: Varsei and Polyakovskiy researched the wine industry, while this paper focused on the Baijiu industry. (2) Country background: Varsei and Polyakovskiy focused on Australia, while this work was in China. (3) Network: Varsei and Polyakovskiy focused on bottling plant location problem, while this study focused on distribution center issues. (4) Model: There are many differences between Varsei and 


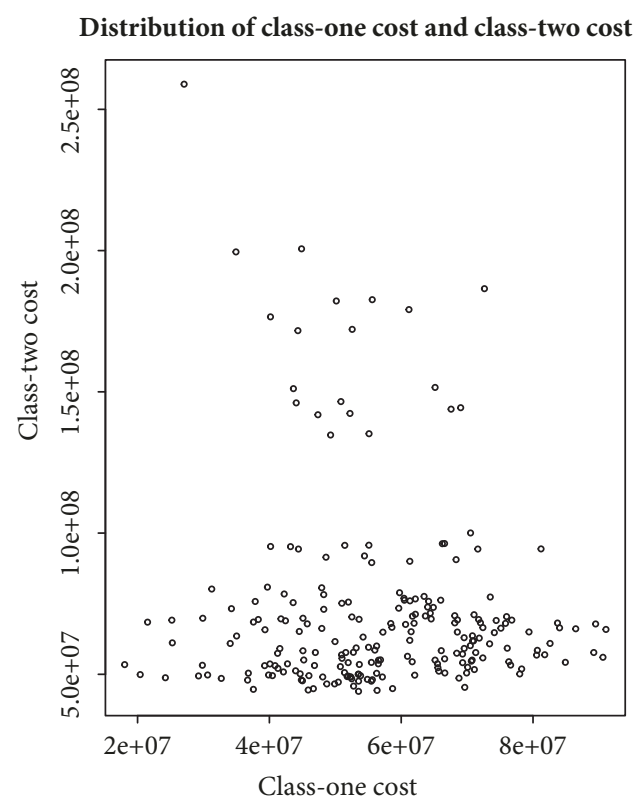

(a) Scatter diagram of class one cost and class two cost

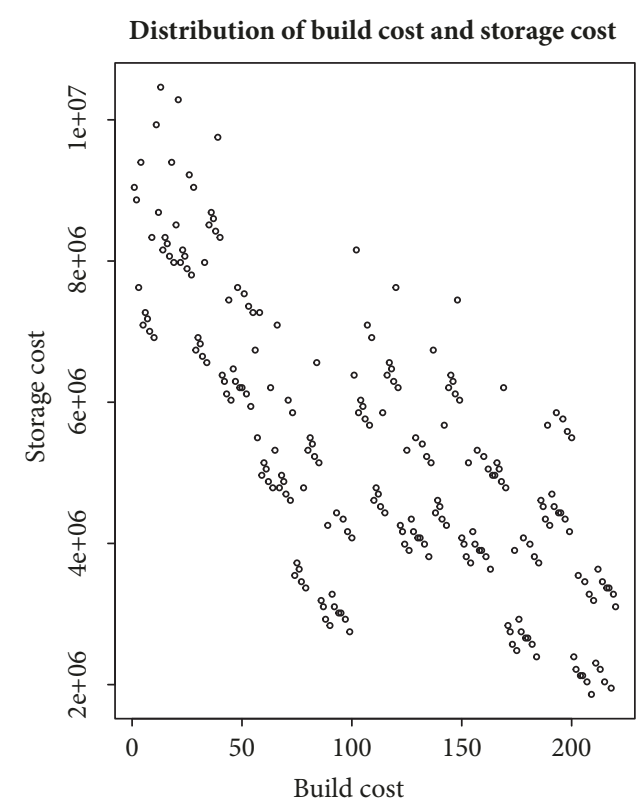

(b) Scatter diagram of build cost and storage cost

Figure 8: Scatter diagrams of costs, S1.

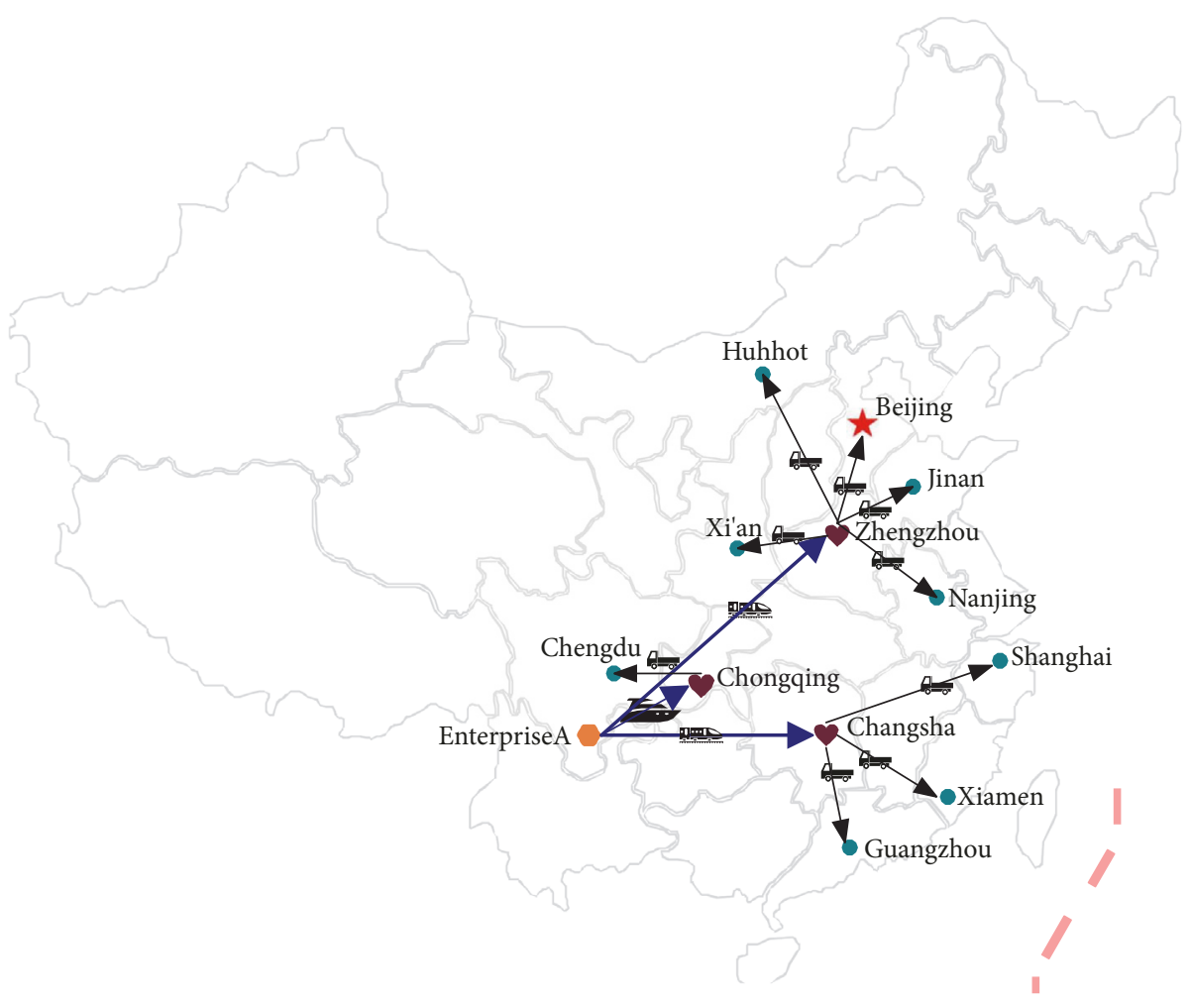

FIGURE 9: Optimal solution for minimizing the environmental impact of Enterprise A, S2.

Polyakovskiy's model and the model suggested in this paper. The Baijiu supply chain economic dimension must consider the total waste disposal costs at the distillery, the pot bottom water and waste water from Baijiu production process, and the total byproduct credit obtained from selling vinasse. For the environmental dimension, Varsei and Polyakovskiy only considered the carbon emissions generated by all supply chain transportation activities, while, in this study, the carbon emissions generated in the production stage and the waste disposal stage were also considered. For the social dimension, 


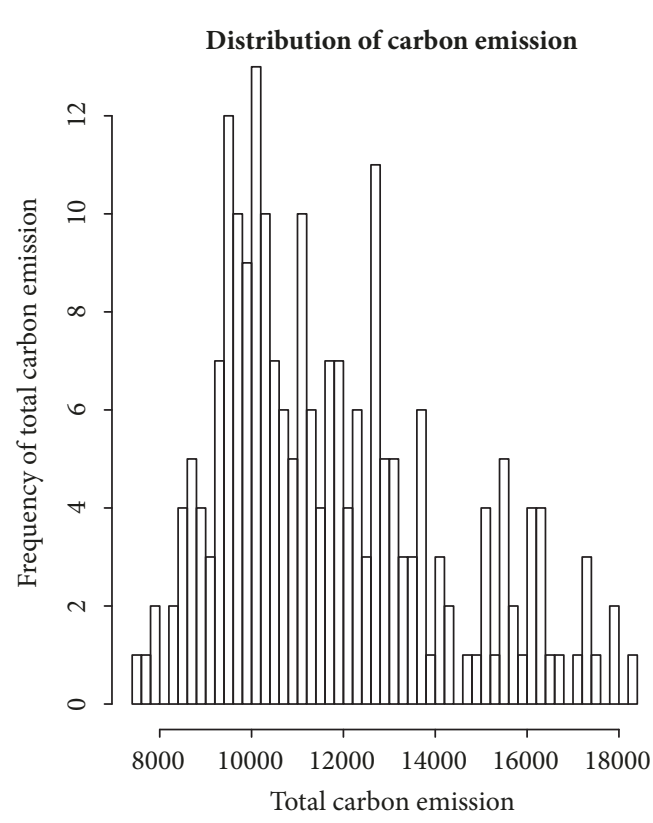

(a) Distribution of carbon emission

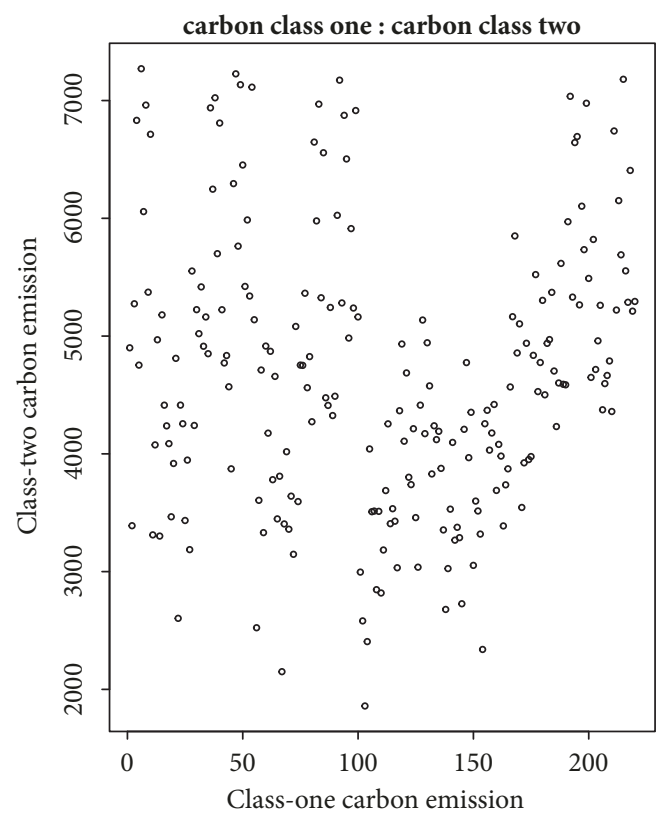

(b) Scatter diagram of class one carbon emission and class two carbon emission

FIGURE 10: Distribution and scatter diagram of carbon emissions, S2.

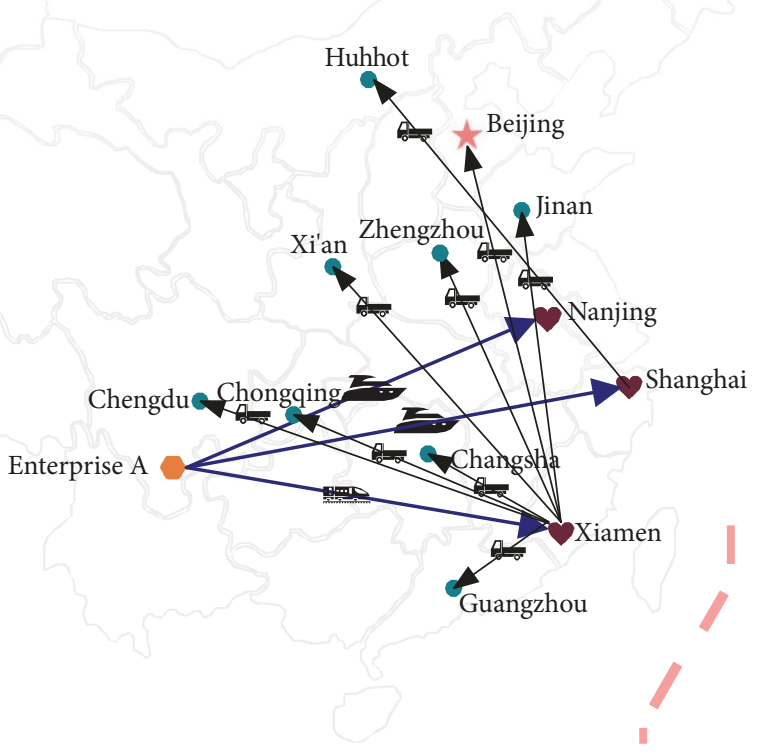

FIGURE 11: Optimal solution by maximizing social influence of Enterprise A, S3. 


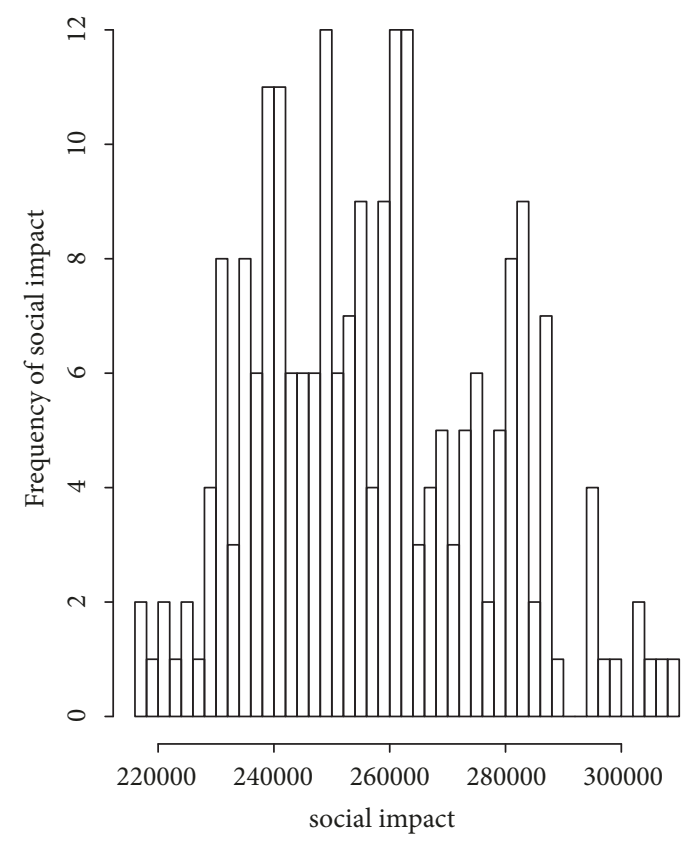

FIGURE 12: Distribution map of social impact, S3.

Varsei and Polyakovskiy used regional GDP to measure regional economic development, while in our study regional per capita GDP was used to measure the cities' economic levels as it was believed that regional per capita GDP was more effective than regional GDP. Further, Varsei and Polyakovskiy did not consider the impact of product quantity, while, in our model, it was believed that product quantity impacted social welfare. The normalization approach was different; Varsei and Polyakovskiy used AHP, while our study used a fuzzy AHP method that was more applicable to this issue. (5) Methods: Varsei and Polyakovskiy used a CPLEX approach to resolve the multiobjective model, while this paper employed $\mathrm{R}$ language to obtain the optimal solution, which was considered to be more suitable for this model. (6) Results: The results in the two papers were different due to different supply chains and methods.

\section{Conclusions}

In this paper, the current status of the Chinese Baijiu industry was presented, for which a multiobjective network design model was developed for the Baijiu industry from a supply chain management perspective. Despite the growing awareness of sustainable supply chain network design, there have been few effective methods that have addressed all three dimensions of sustainability in Baijiu supply chain management. From a comprehensive literature review, expert opinion, and deep understanding of the practical situation, a multiple optimal model was presented which linked sustainability, the Baijiu industry, and supply chain management. To illustrate our method, a real Baijiu industry case study in Sichuan was addressed, the results from which provide new insights for Baijiu supply chain management.
The future of global production and consumption requires new supply chain management systems to improve environmental and social sustainability. To design a more sustainable network, companies need to reconfigure their current supply chain and devise new business models. It is necessary to apply innovative designs to develop more sustainable supply chains for the future. In future work, we wish to propose other evolutionary methods to optimize economic effectiveness, environmental effectiveness, and social effectiveness. The findings of this study will improve the understanding of the relationship between sustainable supply chain network design and the Baijiu industry. The findings also provide insights for policy-makers, scholars, and practitioners in China seeking to improve Baijiu supply chain design to reduce total costs and carbon emissions, promote social health, and develop sustainable transportation modes, with the ultimate aim of moving towards a sustainable future.

\section{Data Availability}

The data used to support the findings of this study are available from the corresponding author upon request.

\section{Conflicts of Interest}

The authors declare that they have no conflicts of interest.

\section{Acknowledgments}

The authors are very grateful to Zhibin $\mathrm{Wu}$ for his constructive comments and valuable suggestions. This work was supported by the National Natural Science Foundation of China under Grants nos. 71671118 and 71702156, the Humanities and Social Sciences of Ministry of Education of China (no. 17YJC630098), the Sichuan Provincial Education Department of Key Research Base Key Program (no. CJZ1702), the Doctoral Fund Project of Sichuan University of Science and Engineering (no. 2017RCSK21), and the General Project of Sichuan Education Department (no. 18SB0400).

\section{References}

[1] H.-Y. Wang, Y.-B. Gao, Q.-W. Fan, and Y. Xu, "Characterization and comparison of microbial community of different typical Chinese liquor Daqus by PCR-DGGE," Letters in Applied Microbiology, vol. 53, no. 2, pp. 134-140, 2011.

[2] X.-W. Zheng, Z. Yan, B.-Z. Han et al., "Complex microbiota of a Chinese 'Fen' liquor fermentation starter (Fen-Daqu), revealed by culture-dependent and culture-independent methods," Food Microbiology, vol. 31, no. 2, pp. 293-300, 2012.

[3] M.-K. Liu, Y.-M. Tang, X.-J. Guo et al., "Deep sequencing reveals high bacterial diversity and phylogenetic novelty in pit mud from Luzhou Laojiao cellars for Chinese strong-flavor Baijiu," Food Research International, vol. 102, pp. 68-76, 2017.

[4] J.-H. Shi, Y.-P. Xiao, X.-R. Li, E.-B. Ma, X.-W. Du, and Z.-X. Quan, "Analyses of microbial consortia in the starter of Fen Liquor," Letters in Applied Microbiology, vol. 48, no. 4, pp. 478485, 2009. 
[5] X.-W. Zheng and B.-Z. Han, "Baijiu, Chinese liquor: history, classification and manufacture," Journal of Ethnic Foods, vol. 3, no. 1, pp. 19-25, 2016.

[6] Y. Han, B. Huang, S. Liu et al., "Residue levels of five grainstorage-use insecticides during the production process of sorghum distilled spirits," Food Chemistry, vol. 206, pp. 12-17, 2016.

[7] D. Zhao, D. Shi, J. Sun et al., "Characterization of key aroma compounds in Gujinggong Chinese Baijiu by gas chromatography-olfactometry, quantitative measurements, and sensory evaluation," Food Research International, vol. 105, pp. 616-627, 2018.

[8] China Industry Information, Market situation and development trend of Chinese Baijiu industry in 2015, 2015, http://www.chyxx .com/industry//352057.html.

[9] F. Q. Zhao, Research on Sustainable Development of Baijiu Industry in China, Graduate School of Chinese Academy of Social Sciences, 2014.

[10] G. Ye, H. Luo, Z. Ren et al., "Evaluating the bioenergy potential of Chinese Liquor-industry waste through pyrolysis, thermogravimetric, kinetics and evolved gas analyses," Energy Conversion and Management, vol. 163, pp. 13-21, 2018.

[11] D. O'Rourke, “The science of sustainable supply chains," Science, vol. 344, no. 6188, pp. 1124-1127, 2014.

[12] J. Gao and F. You, "Modeling framework and computational algorithm for hedging against uncertainty in sustainable supply chain design using functional-unit-based life cycle optimization," Computers \& Chemical Engineering, vol. 107, pp. 221-236, 2017.

[13] A. P. Barbosa-Povoa, C. da Silva, and A. Carvalho, "Opportunities and challenges in sustainable supply chain: an operations research perspective," European Journal of Operational Research, vol. 268, no. 2, pp. 399-431, 2018.

[14] S. Bairamzadeh, M. S. Pishvaee, and M. Saidi-Mehrabad, "Multiobjective Robust Possibilistic Programming Approach to Sustainable Bioethanol Supply Chain Design under Multiple Uncertainties," Industrial \& Engineering Chemistry Research, vol. 55, no. 1, pp. 237-256, 2016.

[15] G. Corsano, A. R. Vecchietti, and J. M. Montagna, "Optimal design for sustainable bioethanol supply chain considering detailed plant performance model," Computers \& Chemical Engineering, vol. 35, no. 8, pp. 1384-1398, 2011.

[16] B. Mota, M. I. Gomes, A. Carvalho, and A. P. Barbosa-Povoa, "Sustainable supply chains: An integrated modeling approach under uncertainty," OMEGA - The International Journal of Management Science, vol. 77, pp. 32-57, 2018.

[17] H. Reefke and D. Sundaram, "Key themes and research opportunities in sustainable supply chain management - identification and evaluation," OMEGA - The International Journal of Management Science, vol. 66, pp. 195-211, 2017.

[18] M. Varsei and S. Polyakovskiy, "Sustainable supply chain network design: A case of the wine industry in Australia," OMEGA - The International Journal of Management Science, vol. 66, pp. 236-247, 2017.

[19] M. K. Lim, H.-Y. Mak, and Z.-J. M. Shen, "Agility and proximity considerations in supply chain design," Management Science, vol. 63, no. 4, pp. 1026-1041, 2017.

[20] Y. Shu and J. Cai, ““Alcohol Bans”: Can they reveal the effect of Xi Jinping's anti-corruption campaign?” European Journal of Political Economy, vol. 50, pp. 37-51, 2017.
[21] S. Seuring, "A review of modeling approaches for sustainable supply chain management," Decision Support Systems, vol. 54, no. 4, pp. 1513-1520, 2013.

[22] M. Brandenburg, K. Govindan, J. Sarkis, and S. Seuring, "Quantitative models for sustainable supply chain management: developments and directions," European Journal of Operational Research, vol. 233, no. 2, pp. 299-312, 2014.

[23] C. R. Carter and P. L. Easton, "Sustainable supply chain management: Evolution and future directions," International Journal of Physical Distribution and Logistics Management, vol. 41, no. 1, pp. 46-62, 2011.

[24] P. Zhao, B. Liu, L. Xu, and D. Wan, "Location optimization of multidistribution centers based on low-carbon constraints," Discrete Dynamics in Nature and Society, vol. 2013, 2013.

[25] J. Xu, Q. Liu, and R. Wang, "A class of multi-objective supply chain networks optimal model under random fuzzy environment and its application to the industry of Chinese liquor," Information Sciences, vol. 178, no. 8, pp. 2022-2043, 2008.

[26] M. Eskandarpour, P. Dejax, J. Miemczyk, and O. Péton, "Sustainable supply chain network design: An optimization-oriented review," OMEGA - The International Journal of Management Science, vol. 54, pp. 11-32, 2015.

[27] X. Ding, C. Wu, J. Huang, and R. Zhou, "Characterization of interphase volatile compounds in Chinese Luzhou-flavor liquor fermentation cellar analyzed by head space-solid phase micro extraction coupled with gas chromatography mass spectrometry (HS-SPME/GC/MS)," LWT-Food Science and Technology, vol. 66, pp. 124-133, 2016.

[28] X.-W. Zheng, Z. Yan, M. J. R. Nout et al., "Characterization of the microbial community in different types of Daqusamples as revealed by 16 S rRNA and 26 S rRNA gene clone libraries," World journal of microbiology \& biotechnology, vol. 31, no. 1, pp. 199208, 2015.

[29] F. You, L. Tao, D. J. Graziano, and S. W. Snyder, “Optimal design of sustainable cellulosic biofuel supply chains: Multiobjective optimization coupled with life cycle assessment and input-output analysis," AIChE Journal, vol. 58, no. 4, pp. 1157-1180, 2012.

[30] B. Mota, M. I. Gomes, A. Carvalho, and A. P. Barbosa-Povoa, "Towards supply chain sustainability: Economic, environmental and social design and planning," Journal of Cleaner Production, vol. 105, pp. 14-27, 2015.

[31] P. J. J. F. Torfs and C. C. Brauer, "A (very) short introduction to R," in Horticulture I: Introduction to Horticulture Vegetable production, 2012.

[32] D. Schmidt, W.-C. Chen, M. A. Matheson, and G. Ostrouchov, "Programming with BIG Data in R: Scaling Analytics from One to Thousands of Nodes," Big Data Research, vol. 8, pp. 1-11, 2017.

[33] K. Govindan, M. Fattahi, and E. Keyvanshokooh, "Supply chain network design under uncertainty: a comprehensive review and future research directions," European Journal of Operational Research, vol. 263, no. 1, pp. 108-141, 2017.

[34] B. Fahimnia, M. Reisi, T. Paksoy, and E. Özceylan, "The implications of carbon pricing in Australia: An industrial logistics planning case study," Transportation Research Part D: Transport and Environment, vol. 18, no. 1, pp. 78-85, 2013.

[35] Ž. Zore, L. Uek, and Z. Kravanja, "Syntheses of sustainable supply networks with a new composite criterion CSustainability profit," Computers Chemical Engineering, vol. 102, pp. 139-155, 2017.

[36] R. Agarwal and Ö. Ergun, "Network design and allocation mechanisms for carrier alliances in liner shipping," Operations Research, vol. 58, no. 6, pp. 1726-1742, 2010. 
[37] Y. Zhong, J. Shu, W. Xie, and Y. Zhou, "Optimal trade credit and replenishment policies for supply chain network design," Omega , vol. 81, pp. 26-37, 2018.

[38] A. Ramudhin, A. Chaabane, M. Kharoune, and M. Paquet, "Design of sustainable supply chains under the emission trading scheme," International Journal of Production Economics, vol. 135, no. 1, pp. 37-49, 2012.

[39] K. Govindan, A. Jafarian, and V. Nourbakhsh, "Bi-objective integrating sustainable order allocation and sustainable supply chain network strategic design with stochastic demand using a novel robust hybrid multi-objective metaheuristic," Computers \& Operations Research, 2015.

[40] M. Lenzen, D. Moran, K. Kanemoto, B. Foran, L. Lobefaro, and A. Geschke, "International trade drives biodiversity threats in developing nations," Nature, vol. 486, no. 7401, pp. 109-112, 2012.

[41] A. Y. Hoekstra and T. O. Wiedmann, "Humanity's unsustainable environmental footprint," Science, vol. 344, no. 6188, pp. 11141117, 2014.

[42] J. Wang, X. Cheng, and S. Zhang, "Low carbon distribution channel coordination with a capital-constrained retailer," Discrete Dynamics in Nature and Society, Art. ID 9579348, 13 pages, 2018.

[43] O. İ. Kolak, O. Feyzioğlu, and N. Noyan, "Bi-level multi-objective traffic network optimisation with sustainability perspective," Expert Systems with Applications, vol. 104, pp. 294-306, 2018.

[44] W. Jiang and X. Chen, "Optimal strategies for low carbon supply chain with strategic customer behavior and green technology investment," Discrete Dynamics in Nature and Society, Art. ID 9645087, 13 pages, 2016.

[45] S. F. Ji and R. J. Luo, "A Hybrid Estimation of Distribution Algorithm for Multi-Objective Multi-Sourcing Intermodal Transportation Network Design Problem Considering Carbon Emissions," Sustainability, vol. 9, no. 7, p. 1133, 2017.

[46] G. Guillén-Gosálbez and I. E. Grossmann, "Optimal design and planning of sustainable chemical supply chains under uncertainty," AIChE Journal, vol. 55, no. 1, pp. 99-121, 2009.

[47] Q. Zhang, N. Shah, J. Wassick, R. Helling, and P. Van Egerschot, "Sustainable supply chain optimisation: An industrial case study," Computers \& Industrial Engineering, vol. 74, no. 1, pp. 68-83, 2014.

[48] J. Q. Frota Neto, J. M. Bloemhof-Ruwaard, J. A. E. E. van Nunen, and E. van Heck, "Designing and evaluating sustainable logistics networks," International Journal of Production Economics, vol. 111, no. 2, pp. 195-208, 2008.

[49] M. Varsei, C. Soosay, B. Fahimnia, and J. Sarkis, "Framing sustainability performance of supply chains with multidimensional indicators," Supply Chain Management Review, vol. 19, no. 3, pp. 242-257, 2014.

[50] M. Ferrara, M. Khademi, M. Salimi, and S. Sharifi, "A dynamic Stackelberg game of supply chain for a corporate social responsibility," Discrete Dynamics in Nature and Society, Art. ID 8656174, 8 pages, 2017.

[51] M. S. Pishvaee, J. Razmi, and S. A. Torabi, "Robust possibilistic programming for socially responsible supply chain network design: a new approach," Fuzzy Sets and Systems, vol. 206, pp. $1-20,2012$.

[52] B. Ageron, A. Gunasekaran, and A. Spalanzani, "Sustainable supply management: an empirical study," International Journal of Production Economics, vol. 140, no. 1, pp. 168-182, 2012.
[53] J. Gao and F. You, "Design and optimization of shale gas energy systems: Overview, research challenges, and future directions," Computers \& Chemical Engineering, vol. 106, pp. 699-718, 2017.

[54] K. Petridis, E. Grigoroudis, and G. Arabatzis, "A goal programming model for a sustainable biomass supply chain network," International Journal of Energy Sector Management, vol. 12, no. 1, pp. 79-102, 2018.

[55] L. E. Hombach, C. Busing, and G. Walther, "Robust and sustainable supply chains under market uncertainties and different risk attitudes-a case study of the German biodiesel market," European Journal of Operational Research, 2017.

[56] L. Bals and W. L. Tate, "Sustainable Supply Chain Design in Social Businesses: Advancing the Theory of Supply Chain," Journal of Business Logistics, vol. 39, no. 1, pp. 57-79, 2018.

[57] R. G. Eccles, I. Ioannou, and G. Serafeim, "The impact of corporate sustainability on organizational processes and performance," Management Science, vol. 60, no. 11, pp. 2835-2857, 2014.

[58] M. Zha, B. Sun, Y. Wu, S. Yin, and C. Wang, "Improving flavor metabolism of Saccharomyces cerevisiae by mixed culture with Wickerhamomyces anomalus for Chinese Baijiu making," Journal of Bioscience and Bioengineering, 2018.

[59] X.-R. Li, E.-B. Ma, L.-Z. Yan et al., "Bacterial and fungal diversity in the traditional Chinese liquor fermentation process," International Journal of Food Microbiology, vol. 146, no. 1, pp. 31-37, 2011.

[60] J. Net, Analysis of the current status of liquor industry in 2014, 2014, http://www.jianiang.cn/yanjiu/D32014_6.html.

[61] L. E. Hombach, C. Busing, and G. Walther, "Robust and sustainable supply chains under market uncertainties and different risk attitudes-a case study of the German biodiesel market," European Journal of Operational Research, vol. 269, no. 1, pp. 302-312, 2018. 


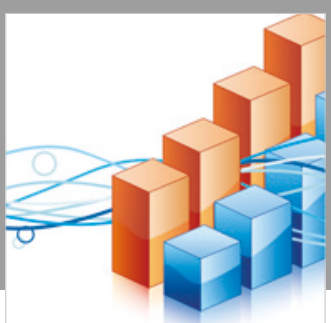

Advances in

Operations Research

\section{-n-m}
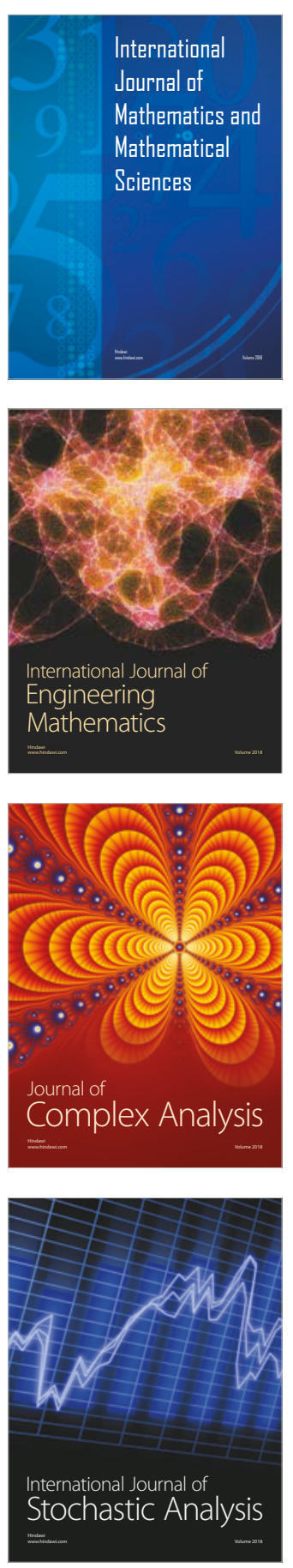
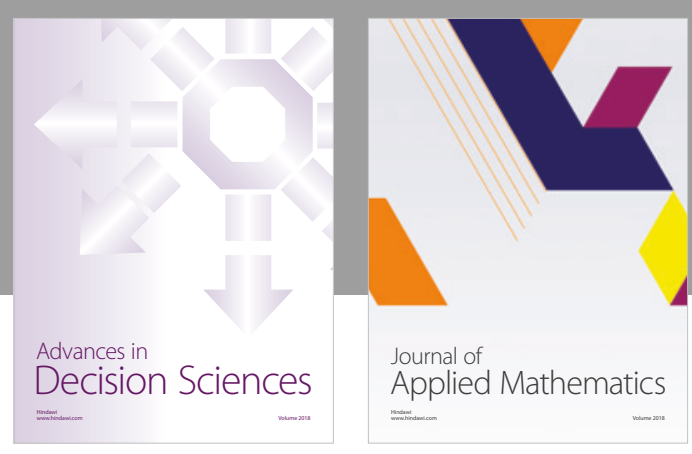

Journal of

Applied Mathematics
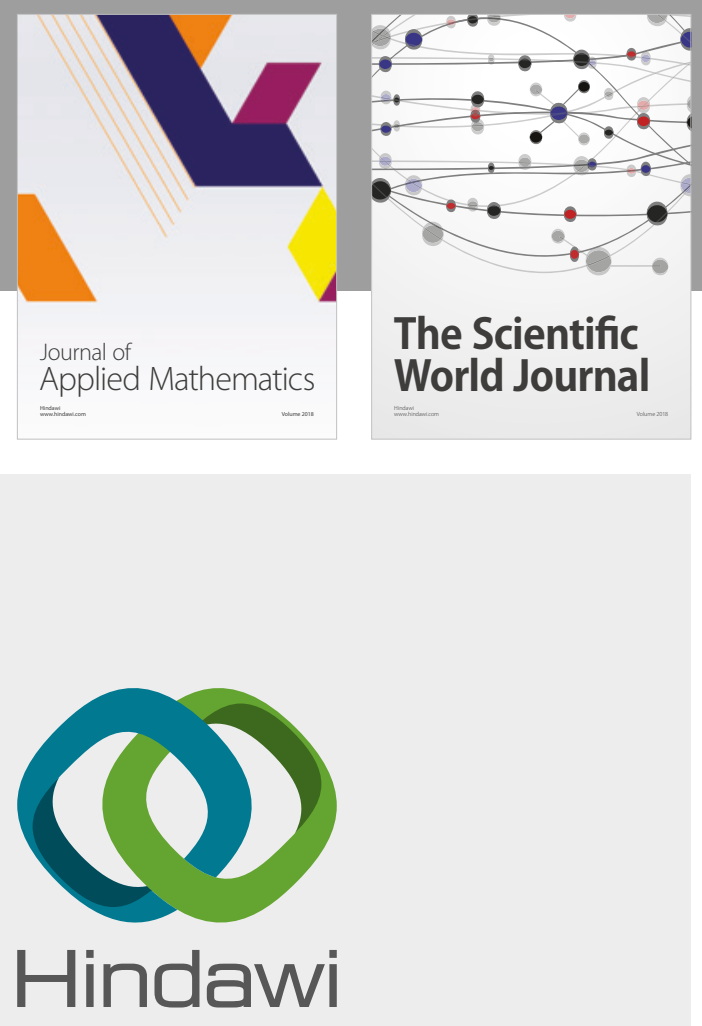

Submit your manuscripts at

www.hindawi.com

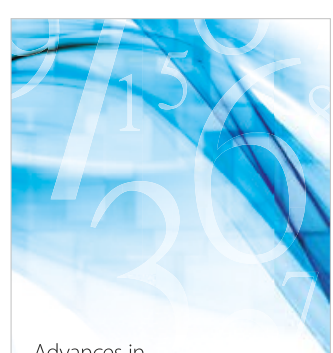

Advances in
Numerical Analysis
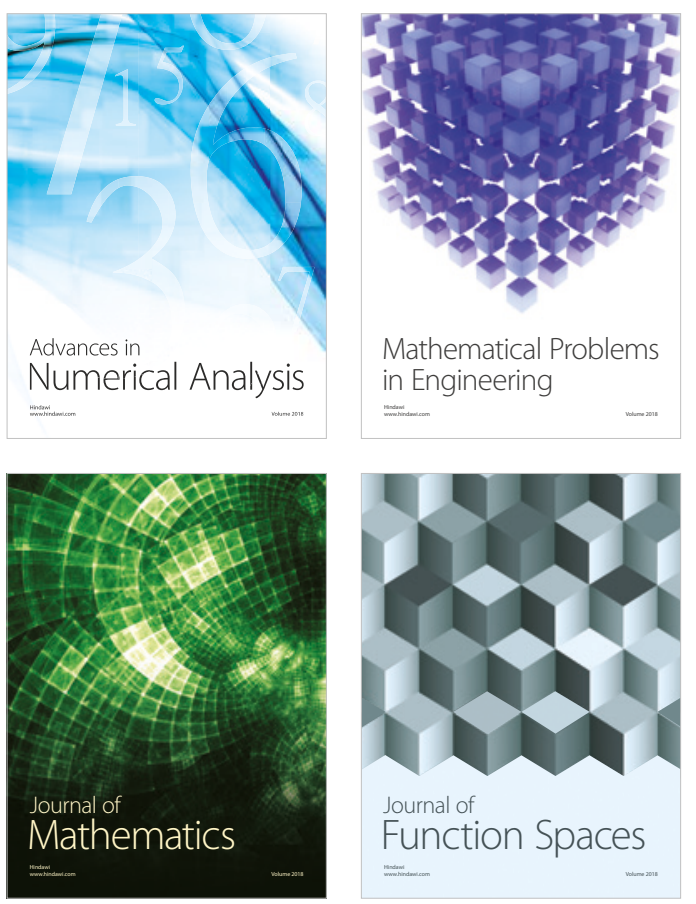

Mathematical Problems in Engineering

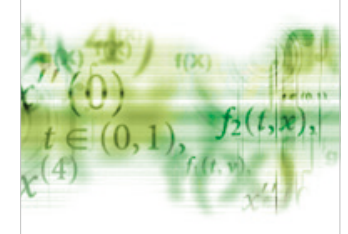

International Journal of

Differential Equations

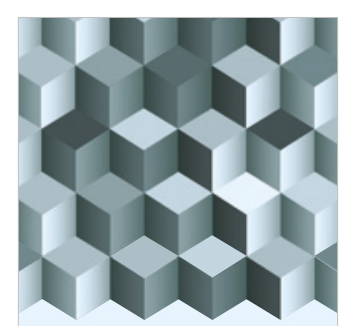

Journal of

Function Spaces

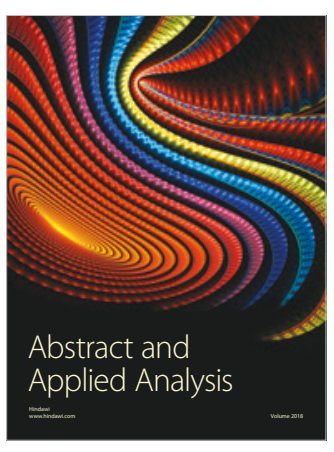

The Scientific

World Journal

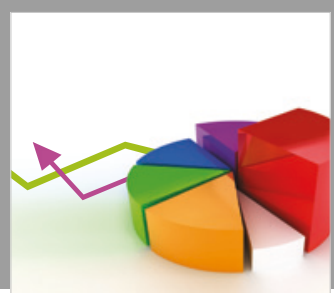

Journal of

Probability and Statistics
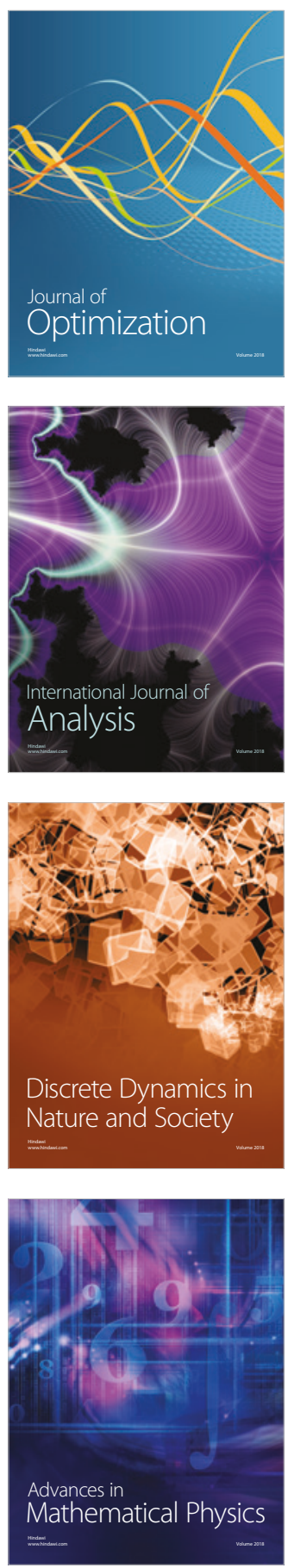